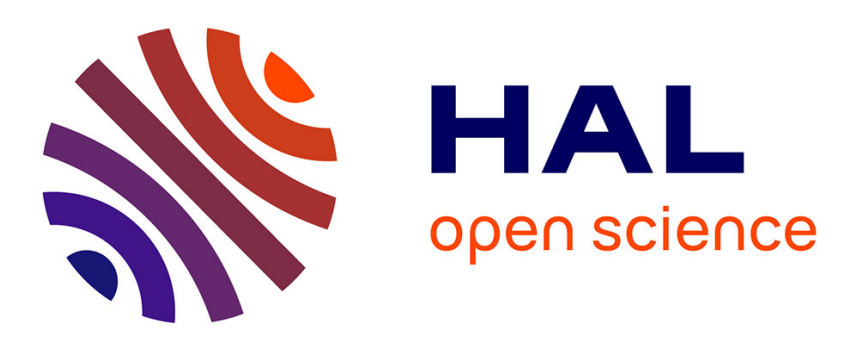

\title{
Comparison of extracellular matrix enrichment protocols for the improved characterization of the skin matrisome by mass spectrometry
}

Mélissa Dussoyer, Adeline Page, Frédéric Delolme, Patricia Rousselle, Alexander Nyström, Catherine Moali

\section{To cite this version:}

Mélissa Dussoyer, Adeline Page, Frédéric Delolme, Patricia Rousselle, Alexander Nyström, et al.. Comparison of extracellular matrix enrichment protocols for the improved characterization of the skin matrisome by mass spectrometry. Journal of Proteomics, 2022, 251, pp.104397. 10.1016/j.jprot.2021.104397 . hal-03414236

\author{
HAL Id: hal-03414236 \\ https://hal.science/hal-03414236
}

Submitted on 4 Nov 2021

HAL is a multi-disciplinary open access archive for the deposit and dissemination of scientific research documents, whether they are published or not. The documents may come from teaching and research institutions in France or abroad, or from public or private research centers.
L'archive ouverte pluridisciplinaire HAL, est destinée au dépôt et à la diffusion de documents scientifiques de niveau recherche, publiés ou non, émanant des établissements d'enseignement et de recherche français ou étrangers, des laboratoires publics ou privés. 
Comparison of extracellular matrix enrichment protocols for the improved characterization of the skin matrisome by mass spectrometry

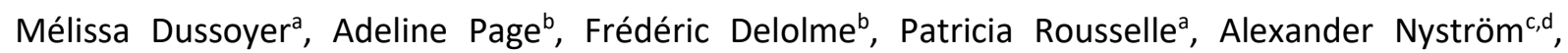
Catherine Moali

aUniversity of Lyon, CNRS, Tissue Biology and Therapeutic Engineering Laboratory, LBTI, UMR5305, F69367 Lyon, France

'University of Lyon, INSERM, ENS Lyon, CNRS, Protein Science Facility, SFR BioSciences, UAR3444/US8, F-69366 Lyon, France

'Department of Dermatology, Medical Faculty, Medical Center - University of Freiburg, Freiburg, Germany

${ }^{\mathrm{d} F r e i b u r g}$ Institute for Advanced Studies (FRIAS), University of Freiburg, Freiburg, Germany

Address correspondence to Catherine Moali: catherine.moali@ibcp.fr

Tissue Biology and Therapeutic Engineering Laboratory - LBTI

7, Passage du Vercors - 69367 Lyon Cedex 07 - France

Authors' contributions: MD: investigation, methodology, writing - original draft; FD, AP: investigation, resources, writing - review and editing; PR, AN: funding acquisition, writing - review and editing; $C M$ : funding acquisition, investigation, methodology, supervision, writing - original draft.

\section{Acknowledgements}

We thank Christelle Bonod, Nicolas Picard and Laura Prigent (LBTI, University of Lyon, France) for their help with the mouse work and skin sample collection.

\section{Funding}

This work was supported by the French and German Research Agencies (grants ANR-18-CE92-0035 to CM and DFG NY90/5-1 to AN), the CNRS and the University of Lyon. We also thank ITMO Cancer AVIESAN for the funding of the Orbitrap mass spectrometer.

\section{Graphical Abstract}

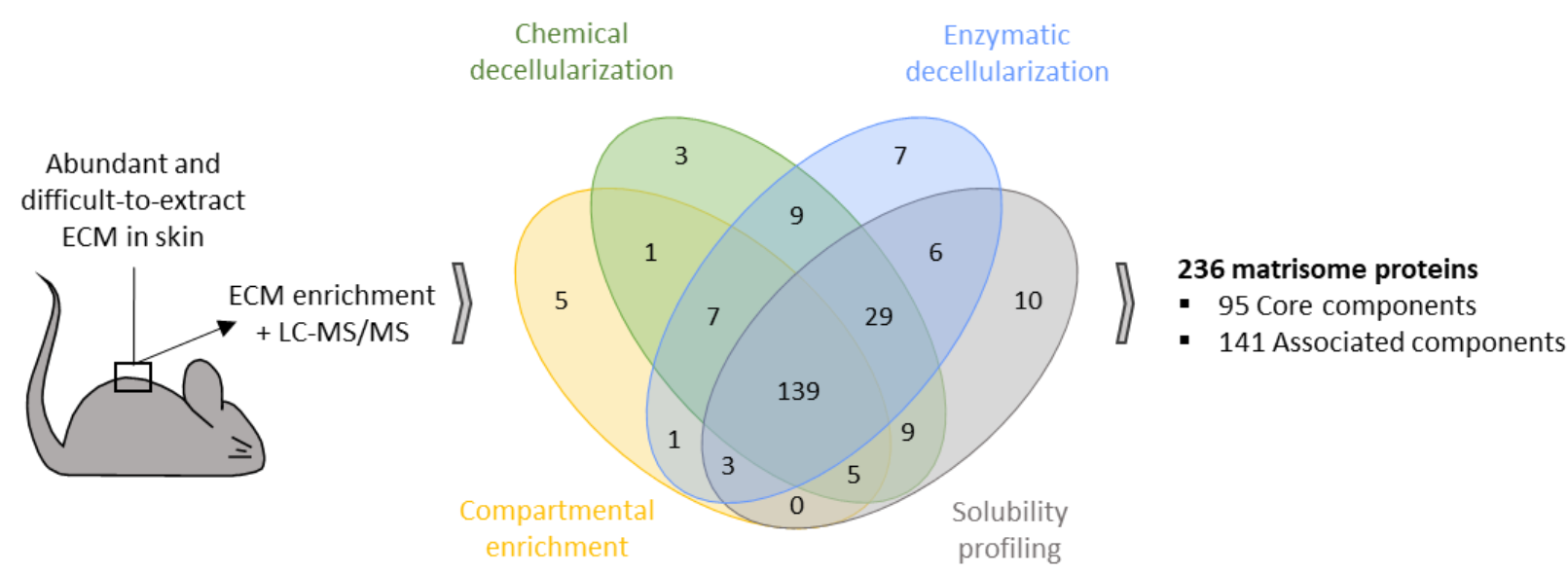




\begin{abstract}
A striking feature of skin organization is that the extracellular matrix (ECM) occupies a larger volume than the cells. Skin ECM also directly contributes to aging and most cutaneous diseases. In recent years, specific ECM enrichment protocols combined with in silico approaches allowed the proteomic description of the matrisome of various organs and tumour samples. Nevertheless, the skin matrisome remains under-studied and protocols allowing the efficient recovery of the diverse ECM found in skin are still to be described. Here, we compared four protocols allowing the enrichment of ECM proteins from adult mouse back skin and found that all protocols led to a significant enrichment (up to $65 \%$ ) of matrisome proteins when compared to total skin lysates. The protocols based on decellularization and solubility profiling gave the best results in terms of numbers of proteins identified and confirmed that skin matrisome proteins exhibit very diverse solubility and abundance profiles. We also report the first description of the skin matrisome of healthy adult mice that includes 236 proteins comprising 95 core matrisome proteins and 141 associated matrisome proteins. These results provide a reliable basis for future characterizations of skin ECM proteins and their dysregulations in disease-specific contexts.
\end{abstract}

\title{
Significance
}

Extracellular matrix proteins are key players in skin physiopathology and have been involved in several diseases such as genetic disorders, wound healing defects, scleroderma and skin carcinoma. However, skin ECM proteins are numerous, diverse and challenging to analyze by mass spectrometry due to the multiplicity of their post-translational modifications and to the heterogeneity of their solubility profiles. Here, we performed the thorough evaluation of four ECM enrichment protocols compatible with the proteomic analysis of mouse back skin and provide the first description of the adult mouse skin matrisome in homeostasis conditions. Our work will greatly facilitate the future characterization of skin ECM alterations in preclinical mouse models and will inspire new optimizations to analyze the skin matrisome of other species and of human clinical samples.

\section{Highlights}

- Four ECM enrichment protocols were applied to mouse skin and compared by LC-MS/MS

- Skin matrisome coverage was greatly and reproducibly improved with all protocols

- Both core and associated matrisome components benefit from enrichment

- Associated matrisome components are better enriched in mild buffers

- 236 matrisome proteins were identified in the skin of healthy adult mice 


\section{Introduction}

Skin is the one of the largest organs in mammals. It provides protection against water loss and biological, chemical and physical assaults [1]. These properties are conferred on skin by its specific tissue architecture consisting of two main layers: the epidermis, a stratified squamous epithelium which provides the barrier function, and the dermis which mainly consists of a dense extracellular matrix (ECM), synthesized by fibroblasts, and responsible for skin mechanical strength and elasticity. At the interface between the epidermis and dermis is the dermal-epidermal junction (DEJ), a thin network of specialized ECM components involved in maintaining the dermal-epidermal cohesion $[2,3]$.

ECM structural proteins are the main components of the dermis and DEJ. They comprise collagens, proteoglycans and glycoproteins that all share the common ability to participate in supramolecular assemblies [4]. Collagens have triple helical domains and can form a large variety of networks [5,6], from large fiber bundles (collagens I, III, V) or microfibrils (collagen VI) in the dermis to anchoring fibrils (collagen VII) or lattice networks (collagen IV) in the DEJ. Proteoglycans are decorated by long glycosaminoglycan chains with specific binding properties [7]. They regulate collagen fibrillogenesis, as is the case for small leucine-rich proteoglycans (SLRPs, e.g. decorin, biglycan, fibromodulin), play major roles in angiogenesis (perlecan) and act as signaling molecules or as reservoirs/antagonists for signaling molecules [8-10]. Glycoproteins are a more heterogeneous group of proteins which can also form supramolecular networks, such as fibrils for fibronectin in the dermis or anchoring filaments for laminin 332 in the DEJ. Besides, they are often involved in interactions with other ECM proteins to regulate matrix architecture and cell behavior (e.g. fibrillins, thrombospondins, tenascins, periostin) $[8,11]$. Notably, the three types of ECM structural proteins display some degree of overlap as some collagens are decorated with glycosaminoglycan chains (e.g. collagen XVIII) and O- and Nglycosylations are not only found in glycoproteins but also in collagens and proteoglycans.

In addition to these well-characterized structural proteins, many additional proteins are found in variable amounts in the ECM and are critical players in the control of skin homeostasis and in responses to injury or stress signals. These include the numerous extracellular enzymes involved in ECM biosynthesis or degradation (procollagen proteinases, matrix metalloproteinases and cross-linking enzymes) [5,12,13], inhibitors of these enzymes (serpins, cystatins and tissue inhibitors of metalloproteinases or TIMPs) [14], growth factors, cytokines or angiogenic molecules stored in the ECM (e.g. TGF- $\beta$, chemokines, VEGF) [9]. Components released from the cell surface can also bind to ECM components and contribute to regulate ECM-dependent signaling (e.g. CD109, glypicans, annexins) [15-17].

In order to better define ECM and ECM-associated proteins, a systematic approach combining the in silico analysis of protein domains with an extensive literature review has been proposed a few years ago [18]. In human and mouse, more than 1000 proteins were selected to define the "matrisome" and grouped in two main subcategories. The "core matrisome" is composed of architectural proteins namely collagens, proteoglycans and glycoproteins, as described above. The "associated matrisome" comprises ECM regulators, secreted factors and ECM-affiliated proteins. These lists have proven very useful to annotate omics data and now serve as references for the analysis of the ECM composition of diverse tissues and organisms [19].

In parallel, new protocols have been developed to better extract ECM proteins, which are often insoluble and highly cross-linked. Among them, a method based on the successive extraction of proteins found in different cell compartments to yield an insoluble pellet enriched in ECM components [20] has been widely used and shown to be compatible with proteomic analysis. This approach helped to identify the matrix content of healthy and diseased tissues in human and mouse, including 
pancreatic islets [21], breast [22], lung [23], liver and colon [24]. The main pitfall of this approach is the loss of loosely-bound ECM components. Another method based on protein solubilization in buffers containing increasing detergent concentrations (named quantitative detergent solubility profiling or QDSP) was also developed and found to give very good matrisome coverage of the lung tissue [25]. Finally, protocols based on tissue decellularization, using detergents $[26,27]$ or enzymes such as phospholipase A2 (PLA2) [28], which were initially developed for the analysis of the ECM from cardiovascular tissues or the production of acellular scaffolds [29], also proved efficient to enrich matrisome proteins and facilitate their identification by tandem mass spectrometry (MS/MS). These decellularization protocols were recently applied to human skin and led to the identification of between 137 and 267 ECM proteins [28,30,31]. However, when applied to rat skin, the PLA2 decellularization approach only yielded 102 matrisome proteins [28], suggesting that it may not be optimal to analyze murine skin.

Here, we compared four ECM enrichment protocols with a more classical skin lysis method in order to optimize skin matrisome recovery for MS-based proteomics. We then investigated the nature of identified matrisome proteins and their distribution among the fractions generated by the various enrichment methods. Finally, we combined all the data to generate the first experimentally-based, detailed description of the mouse skin matrisome.

\section{Material and methods}

\section{Chemicals}

$\mathrm{NaCl}$ (1112-A) and HEPES (10-110) were purchased from Euromedex. Acetonitrile (ACN; 34998), calcium chloride (2233506), chloroform (34854), dithiothreitol (DTT; D0632), DNAse I (04536282001), ethylenediaminetetraacetic acid (EDTA; E5134), formic acid (33015), glycerol (G9012), guanidinium hydrochloride (GuHCl; G4630), NP-40 (I3021), iodoacetamide (I1149), magnesium chloride (M1028), $\beta$-mercaptoethanol (M7154), methanol (34860), phospholipase A2 (PLA2; P9279), cOmplete ${ }^{\mathrm{TM}}$ protease inhibitor cocktail (11836153001, prepared according to the manufacturer's instructions), cOmplete $^{T M}$ EDTA-free protease inhibitor cocktail (11836170001, prepared according to manufacturer's instructions), sterile phosphate buffered saline solution (PBS; D8537), sodium acetate (S2889), sodium deoxycholate (SD; D6750), sodium dodecyl sulfate (SDS; L3771), sodium hydroxide (NaOH; S5881), trifluoroacetic acid (TFA; 91707), TRIS-HCl (T3253), Triton X-100 (T8787) and urea (33247) were from Merck. PNGase-F (P0709S), Lys-C (12505061) and trypsin (V5111) were purchased from New-England Biolabs, Promega and Wako respectively. All solutions were prepared in ultra-pure water or in dedicated buffers supplied by the manufacturer and sterilized by $0.22 \mu \mathrm{m}$-filtration.

\section{Skin samples}

Animal experiments followed governmental and international guidelines. Mouse back skin biopsies were collected from pathogen- and disease-free C57BL/6J animals (22 weeks-old) obtained from the Jackson Laboratory. After sacrifice, the back skin was shaved and depilated twice using depilatory cream (3059944026734, Veet). The skin was dissected using scissors and separated from the underlying tissues, taking care of removing as much subcutaneous fat as possible, and stored in Eppendorf LoBind tubes. Tissues were flash-frozen by immersion in liquid nitrogen and stored at -80 ${ }^{\circ} \mathrm{C}$ until use. 


\section{Extraction of matrisome proteins}

Four protocols were adapted and compared to enrich ECM proteins from mouse skin (Fig. 1): 1. compartmental enrichment [20]; 2. chemical decellularization (adapted from [27,32]); 3. enzymatic decellularization using phospholipase A2 (adapted from [33,34]); 4. quantitative detergent solubility profiling (QDSP) [25]. All four protocols were started the same day, each using $35 \mathrm{mg}$ of frozen back skin, sampled from the same initial back skin piece. The experiment was repeated three times starting from three different mice.

- Compartmental enrichment: skin samples were processed using the CNMCS commercial kit (2145, Merck Millipore), as previously described [20], to progressively remove cellular proteins from the native tissue using combinations of salts and detergents (precise composition unknown, but more information can be found in [20]). Briefly, the skin tissue was homogenized in buffer $\mathrm{C}$ using a Tissuelyser II (Qiagen) and successively incubated under agitation in buffers $\mathrm{W}, \mathrm{N}, \mathrm{M}$ and CS supplemented with the protease inhibitors from the kit. Extractions with buffer $\mathrm{C}$ and final insoluble pellet were kept, flash-frozen immediately after recovery and stored at $80^{\circ} \mathrm{C}$ until MS analysis.

- Chemical decellularization: skin samples were cut into small pieces with a scalpel and gently rotated in $500 \mathrm{mM} \mathrm{NaCl}, 100 \mathrm{mM} \mathrm{HEPES}, \mathrm{pH} 7.4$ for $2 \mathrm{~h} 30$. Samples were then centrifuged for $10 \mathrm{~min}$ at $23^{\circ} \mathrm{C}$ and $16,000 \mathrm{~g}$, and the supernatant was kept aside and replaced by ultra-pure water. After $10 \mathrm{~min}$, water was discarded and the skin was treated with $0.75 \%(\mathrm{w} / \mathrm{v}) \mathrm{SD}$ and $0.3 \%(\mathrm{w} / \mathrm{v})$ SDS for $16 \mathrm{~h}$, then a $1 \%(\mathrm{v} / \mathrm{v})$ Triton X-100 bath was applied for $1 \mathrm{~h}$ to remove remaining cell fragments. The resulting tissue was washed twice in ultra-pure water for $1 \mathrm{~h} 30$ and centrifuged for $10 \mathrm{~min}$ at $23^{\circ} \mathrm{C}$ and $16,000 \mathrm{~g}$. The pellet was finally incubated in $4 \mathrm{M} \mathrm{GuHCl}$ and $50 \mathrm{mM}$ sodium acetate for $72 \mathrm{~h}$. All incubation buffers, including ultra-pure water, were supplemented with cOmplete ${ }^{\mathrm{TM}}$ protease inhibitors and EDTA (to reach a final concentration of $25 \mathrm{mM}$ EDTA). Successive extractions were performed using a Thermomixer (Thermo Fisher Scientific) at $23{ }^{\circ} \mathrm{C}$ and $600 \mathrm{rpm}$. Extractions in $500 \mathrm{mM} \mathrm{NaCl}$, in SD/SDS and in $4 \mathrm{M} \mathrm{GuHCl}$ as well as the final insoluble tissue fragments were kept, flash-frozen immediately after recovery and stored at $-80^{\circ} \mathrm{C}$ until MS analysis.

- Enzymatic decellularization: the first step was the same as in the previous protocol. After the first extraction in $500 \mathrm{mM} \mathrm{NaCl}, 100 \mathrm{mM}$ HEPES pH 7.4, cOmplete ${ }^{\mathrm{TM}}$ protease inhibitors and $25 \mathrm{mM}$ EDTA, chopped skin pieces were washed twice in sterile PBS for $10 \mathrm{~min}$ at $4{ }^{\circ} \mathrm{C}$ and 600 rpm and centrifuged for $10 \mathrm{~min}$ at $4{ }^{\circ} \mathrm{C}$ and $16,000 \mathrm{~g}$. Decellularization was performed using $200 \mathrm{U} / \mathrm{mL}$ PLA2 in $150 \mathrm{mM} \mathrm{NaCl}, 100 \mathrm{mM}$ HEPES pH 7.4 for $18 \mathrm{~h}$ at $37^{\circ} \mathrm{C}, 500 \mathrm{rpm}$. The enzyme incubation buffer was supplemented with $1 \mathrm{mM} \mathrm{MgCl}, 1 \mathrm{mM} \mathrm{CaCl}, 750 \mathrm{U} / \mathrm{mL}$ DNAse I, EDTAfree cOmplete ${ }^{\mathrm{TM}}$ protease inhibitors and $0.5 \% \mathrm{SD}$. The sample was centrifuged for $10 \mathrm{~min}$ at $23^{\circ} \mathrm{C}$ and $16,000 \mathrm{~g}$ and briefly washed with sterile PBS. A final centrifugation was applied for 15 min at $4{ }^{\circ} \mathrm{C}$ and $16,000 \mathrm{~g}$ and PBS was discarded. PLA2/SD extraction solution and final insoluble tissue fragments were kept, flash-frozen immediately after recovery and stored at $80^{\circ} \mathrm{C}$ until MS analysis.

- Quantitative detergent solubility profiling (QDSP): skin samples were first homogenized in sterile PBS with $25 \mathrm{mM}$ EDTA using a TissueLyser II and processed as previously reported [25]. Briefly, the tissue was successively incubated for $20 \mathrm{~min}$ under agitation (300 rpm) in PBS, Buffer 1 (150 mM NaCl, 50 mM TRIS-HCl pH 7.5, 1 mM MgCl $2,5 \%$ Glycerol, $1 \%$ NP-40), Buffer 2 (150 mM NaCl, $50 \mathrm{mM}$ TRIS-HCl pH 7.5, 5 \% Glycerol, $1 \% \mathrm{NP}-40,0.1 \% \mathrm{SDS}, 0.5 \% \mathrm{SD}$ ) at $4{ }^{\circ} \mathrm{C}$ 
and in Buffer 3 (500 mM NaCl, 50 mM TRIS-HCl pH 7.5, 5 \% Glycerol, 1 \% NP-40, 1 \% SDS, 2 \% $\mathrm{SD}$ ) at $23^{\circ} \mathrm{C}$. All buffers were supplemented with cOmplete ${ }^{\mathrm{TM}}$ protease inhibitors and, between extractions, samples were centrifuged for $20 \mathrm{~min}$ at $16,000 \mathrm{~g}$ and $4{ }^{\circ} \mathrm{C}$ except after Buffer 3 for which the temperature was set at $23{ }^{\circ} \mathrm{C}$. All extractions solutions were kept after centrifugation. PBS and Buffer 1 extractions were pooled in equal volumes while other extraction solutions were kept separately. All samples were flash-frozen in liquid nitrogen and stored at $-80^{\circ} \mathrm{C}$ until MS analysis.

For comparison with the four protocols described above, total skin lysates were also prepared for two of the mice. In this case, $20 \mathrm{mg}$ of mouse skin were homogenized using a TissueLyzer II in a lysis buffer containing $4 \%$ SDS, $5 \%$-mercaptoethanol, $12.5 \%$ glycerol, 100 mM TRIS-HCl pH 6.8, supplemented with cOmplete ${ }^{\mathrm{TM}}$ protease inhibitors. Samples were strongly vortexed, boiled for $15 \mathrm{~min}$ and incubated for $30 \mathrm{~min}$ at $23^{\circ} \mathrm{C}$ and $600 \mathrm{rpm}$. Supernatants were then centrifuged for $15 \mathrm{~min}$ at $23^{\circ} \mathrm{C}$ and $16,000 \mathrm{~g}$ to eliminate cell fragments, then flash-frozen in liquid nitrogen and stored at $-80^{\circ} \mathrm{C}$ until MS analysis.

\section{Sample preparation for MS/MS}

$200 \mu \mathrm{L}$ of each liquid extraction sample collected above were precipitated at room temperature using the methanol/chloroform method. Briefly, $800 \mu \mathrm{L}$ of methanol, $200 \mu \mathrm{L}$ of chloroform and $600 \mu \mathrm{L}$ of ultra-pure water were added to each sample and, after vortexing, the mixture was centrifuged for 10 $\min$ at $16,000 \mathrm{~g}$. The upper liquid phase was carefully discarded and $800 \mu \mathrm{L}$ of methanol were added to wash proteins. Samples were strongly vortexed, centrifuged for $10 \mathrm{~min}$ at $16,000 \mathrm{~g}$ and methanol was discarded. Protein pellets were briefly vacuum-dried and solubilized in $55 \mu \mathrm{L}$ of $100 \mathrm{mM} \mathrm{NaOH}$ at room temperature. Protein concentrations were determined using a commercial BCA kit (23225, Thermo Fisher Scientific).

For each liquid fraction, $10 \mu \mathrm{g}$ of proteins were further processed for LC-MS/MS analysis. Proteins were reduced with $10 \mathrm{mM}$ DTT for $40 \mathrm{~min}$ at $60^{\circ} \mathrm{C}$ and alkylated with $25 \mathrm{mM}$ iodoacetamide for $40 \mathrm{~min}$ at $23{ }^{\circ} \mathrm{C}$ in the dark. Samples were diluted 4-fold with $100 \mathrm{mM}$ ammonium bicarbonate $\mathrm{pH} 8.0$ and pH was adjusted to 8.0 with $1.8 \mathrm{M} \mathrm{HEPES} \mathrm{pH} \mathrm{8.0.} \mathrm{Proteins} \mathrm{were} \mathrm{deglycosylated} \mathrm{using} \mathrm{PNGaseF} \mathrm{(10} \mathrm{U)} \mathrm{for}$ $2 \mathrm{~h}$ and digested into peptides by successive treatments with Lys-C (1:150 enzyme to protein mass ratio) for $2 \mathrm{~h}$ and trypsin (1:50) overnight. The following day, trypsin was added again (1:100) and the incubation continued for $2 \mathrm{~h}$. All enzyme treatments were performed at $37^{\circ} \mathrm{C}$ and $700 \mathrm{rpm}$. Samples were acidified to $\mathrm{pH} 2.0$ using 50 \% TFA, desalted on C18 columns (89873, Life Technologies) and vacuum-dried.

Around $5 \mathrm{mg}$ of each insoluble pellet were dissolved in $120 \mu \mathrm{L}$ of $100 \mathrm{mM} \mathrm{NaOH}$, strongly vortexed and incubated for $2 \mathrm{~h}$ at $23{ }^{\circ} \mathrm{C}$ and $600 \mathrm{rpm}$. Proteins were reduced, alkylated and digested as described for liquid samples. Amounts of enzymes were increased as follows to allow the complete digestion of proteins: $50 \mathrm{U}$ PNGaseF, $2 \mu \mathrm{g}$ Lys-C and $2 \mu \mathrm{g}$ or $1 \mu \mathrm{g}$ trypsin for the overnight incubation or the 2-hour treatment, respectively. Samples were acidified to $\mathrm{pH} 2.0$ using $50 \%$ TFA and desalted on $\mathrm{C} 18$ columns. Peptide concentrations in the resulting fractions as well as in the liquid $\mathrm{GuHCl}$ extraction of the chemical decellularization protocol were determined using the Pierce ${ }^{\mathrm{TM}}$ quantitative fluorimetric peptide assay (23290, Thermo Fisher Scientific). $10 \mu \mathrm{g}$ of each sample were used for MS analysis. The $\mathrm{GuHCl}$ extraction and the insoluble fraction of the chemical decellularization protocol were pooled in equal peptide amounts. Samples were finally dried in a vacuum centrifuge. 
Dried samples were resuspended in $20 \mu \mathrm{L}$ of $2 \% \mathrm{ACN} / 0.1 \%$ formic acid and $1 \mu \mathrm{L}$ was injected and loaded on a C18 Acclaim PepMap100 trap-column $0.3 \times 5$ mm, $5 \mu \mathrm{m}, 100 \AA$ (Thermo Fisher Scientific) for $3 \mathrm{~min}$ at $20 \mu \mathrm{L} / \mathrm{min}$ with $2 \%$ ACN, $0.05 \%$ TFA in ultra-pure water and then separated on a C18 Acclaim PepMap100 nano-column, $50 \mathrm{~cm} \times 75 \mathrm{~mm}$ i.d, $2 \mathrm{~mm}, 100 \AA$ (Thermo Fisher Scientific) with a four-step linear gradient from $4 \%$ to $20 \%$ buffer B in 100 min (A: $0.1 \%$ formic acid in ultra-pure water, B: $80 \%$ ACN, $0.1 \%$ formic acid in ultra-pure water), from $20 \%$ to $32 \%$ of $B$ in 20 min and then from $32 \%$ to $90 \%$ of $B$ in $2 \mathrm{~min}$, followed by $90 \%$ of $B$ for $10 \mathrm{~min}$. The flow rate was set at $300 \mathrm{~nL} / \mathrm{min}$. The column oven temperature was kept constant at $40^{\circ} \mathrm{C}$. Peptides were analyzed with an online-coupled Q-Orbitrap mass spectrometer (Q Exactive HF; Thermo Fisher Scientific) in a Top 20 HCD (Higher Collision Dissociation) data-dependent acquisition. The resolution of the survey scan was 60,000 at $\mathrm{m} / \mathrm{z} 200 \mathrm{Th}$ and for MS/MS scan the resolution was set to 15,000 at $\mathrm{m} / \mathrm{z} 200$ Th. Parameters for acquiring HCD MS/MS spectra were as follows: collision energy $=27$ and isolation width $=2 \mathrm{~m} / \mathrm{z}$. Precursor ions with unknown charge state, charge states of 1 and 8 or greater than 8 were excluded. Peptides selected for MS/MS acquisition were then placed on an exclusion list for $20 \mathrm{~s}$ using the dynamic exclusion mode to limit duplicate spectra. Data were processed by database searching using SequestHT (Thermo Fisher Scientific) with Proteome Discoverer 2.4 software (Thermo Fisher Scientific) against the Uniprot mouse database (101 412 entries, December 2020). Precursor and fragment mass tolerance were set to $10 \mathrm{ppm}$ and $0.02 \mathrm{Da}$ respectively. Trypsin was selected as enzyme, and up to 2 missed cleavages were allowed. Acetylation (protein $\mathrm{N}$-terminus, $+42.011 \mathrm{Da}$ ), methionine loss (protein N-terminus, -131.040 Da), carbamidomethylation (Cysteine, +57.021 Da) and oxidation (Methionine, Proline and Lysine, the latter only when indicated, $+15.995 \mathrm{Da}$ ) were set as variable modifications. Peptides were filtered with a false discovery rate of $1 \%$. Protein abundances were obtained by summing intensities of precursor ions and normalized to total peptide counts. Mass spectrometry data have been deposited to the ProteomeXchange Consortium via the PRIDE partner repository [35] with the dataset identifier PXD025842.

\section{Data processing}

Matrisome proteins were annotated using the mouse matrisome lists (available on-line: http://matrisomeproject.mit.edu/; last update: August 2014) [19] and the tools of the on-line platform ProteoRE (http://www.proteore.org/) [36]. Proteins identified by MS/MS were searched against matrisome lists using Uniprot IDs. To confirm the results of this first screening and include new protein variants identified since 2014 and not referenced in the mouse matrisome database, a second search was performed using Gene IDs and then followed by a final manual validation. Heatmaps and Venn diagrams were prepared with ProteoRE.

\section{Results and discussion}

\section{Skin ECM enrichment workflows}

Four protocols dedicated to ECM enrichment or tissue decellularization were selected from literature, based on their user-friendliness and compatibility with MS analysis, and adapted to enrich matrisome proteins from adult mouse skin (Fig. 1). The first protocol (hereafter called the "compartmental enrichment" method) relies on the sequential enrichment of different cellular compartments to yield an insoluble pellet mainly consisting of ECM proteins and is currently used as a reference protocol for matrisome studies [20]. Two other protocols (Fig. 1, "chemical decellularization" and "enzymatic decellularization"), adapted from $[27,32]$ and $[33,34]$ respectively, aim at destabilizing cell membranes 
through the use of detergents or PLA2, to remove cellular components and enhance the recovery of extracellular proteins. Last, the QDSP method consists in successive incubations in buffers with increasing detergent concentrations and extracts both cellular and extracellular proteins according to their solubility [25]. Notably, solubility profiling allowed by the QDSP method and to a lesser extent by the chemical decellularization method, can be an advantage to study ECM proteins that often exist in different forms (precursor proteins, mature proteins, proteolytic products) and are more or less tightly integrated in ECM networks, therefore exhibiting different solubility levels. The composition of all the buffers used in chemical and enzymatic decellularizations or in QDSP are known but the exact composition of the commercial solutions used for compartmental enrichment is proprietary (see the Material and Methods section). All insoluble pellets and the extraction solutions which were the most likely to contain matrisome proteins, based on preliminary MS and western-blot evaluation, were analyzed by LC-MS/MS (Fig. 1). Some fractions, which were found in preliminary experiments to have similar compositions were also pooled and analyzed together (the first two fractions of the QDSP protocol and the last two fractions of the chemical decellularization method).

The number of matrisome proteins identified in mouse skin is strongly increased by enrichment methods

Between 2091 and 2703 proteins were identified by LC-MS/MS with the four ECM enrichment protocols when mouse skin was processed in three biological replicates (Table 1, Supplementary Table 1). Among them, between 161 and 202 proteins corresponded to matrisome components, giving a constant percentage of $8 \%$ of the total number of identified proteins. Very similar numbers of matrisome proteins were respectively obtained using the chemical decellularization (202 proteins), enzymatic decellularization (201 proteins) and QDSP (201 proteins) approaches, while the compartmental enrichment method led to a lower number of identifications (161). Importantly, the choice of a database containing both reviewed and unreviewed sequences was made because some important mouse matrisome proteins such as tenascin $\mathrm{X}, \alpha 3(\mathrm{~V})$ and $\alpha 3(\mathrm{VI})$ collagen chains, trichohyalin, transglutaminase- 6 or ADAMTS-like protein 5 were missed when only reviewed sequences were included.

The comparison of protein identities revealed that 139 matrisome proteins were shared by all enrichment protocols, while a total of 234 matrisome proteins were detected when the results of the four protocols were combined (Fig. 2A). Remarkably, the three most effective methods (chemical and enzymatic decellularizations, QDSP) display $84 \%$ overlap in matrisome components, showing that only minor improvement of matrisome coverage is brought by protocol combination. Furthermore, less only $2.2 \%$ of identified matrisome proteins were specifically identified in the compartmental enrichment method. However, even the least efficient ECM enrichment protocol showed a clear benefit over the analysis of a classical skin lysate as only 122 matrisome components could be annotated (from a total of 1107 identified proteins) in the total lysate analyzed without fractionation (Table 1). Also, only 2 matrisome proteins (Col11a1 and Col25a1) were detected in the total skin lysate but not after enrichment (Supplementary Fig. 1).

The number of 161 matrisome proteins identified with the compartmental enrichment approach compares well with the 113 or 185 proteins detected in mouse lung [23] or pancreatic islets [21] with the same approach. However, the latter analyses were conducted using the insoluble fraction alone; on mouse skin, the study of this single fraction led to the identification of 102 proteins only (Supplementary Fig. 2). A recent study actually suggested that this method leads to high losses of matrisome components in the various extraction buffers when applied to a whole mouse powder [37]. 
In line with this, the analysis of the extraction made with buffer $\mathrm{C}$ actually proved very informative and increased the number of identified matrisome components in mouse skin by $59 \%$ compared to the insoluble fraction alone (Supplementary Fig. 2), suggesting that it contains more loosely-bound ECM components.

Chemical decellularization was previously extensively used to characterize heart and cardiovascular tissues by proteomic analysis [26,38-41] and allowed the identification of between 17 and $328 \mathrm{ECM}$ proteins (note that all authors do not use the same inclusion criteria to label ECM proteins). Interestingly, most of these studies relied mainly on the analysis of the $\mathrm{NaCl}$ and $\mathrm{GuHCl}$ extracts and not on the analysis of the final insoluble pellet to reveal ECM proteins. Thus, the benefit of extending $\mathrm{MS}$ analysis to the first extraction fractions ( $\mathrm{NaCl}$ fraction and to a lesser extent SDS fraction) was also suggested in these reports and is nicely confirmed here. Among the 202 proteins which were detected in mouse skin in total with this protocol, $\mathrm{NaCl}$ and SDS/SD extracts specifically brought 71 matrix proteins (Supplementary Fig. 3). More intriguingly, the PLA2 decellularization method gave significantly better results when applied here to mouse skin than in a previous study on rat skin [28] (201 versus 102 matrisome components).

Finally, we identified 201 matrisome proteins with the QDSP approach while previous studies reported 161 and 435 matrisome components in the ECM-poor mouse brain [42] and ECM-rich mouse lung [25], respectively. Notably, more than 8000 total proteins were identified in these two previous reports but a large panel of basal and disease conditions were characterized and all extractions solutions were analyzed after an additional simplification of the fractions using a quick stage tip fractionation that we did not perform here.

Beyond total protein numbers, it is also interesting to compare peptide spectral matches (PSMs) and protein sequence coverages which give additional information about the comprehensiveness of the analysis. While QDSP led to the highest total number of PSMs for matrisome proteins (Fig. 2B), as expected for the protocol with the largest number of analyzed fractions, chemical decellularization also behaved well for matrisome proteins giving similar numbers of PSMs per fraction. The enzymatic decellularization came after, mostly due to the relative PSM paucity of the PLA2/SD and insoluble fractions, and the compartmental extraction was by far the protocol which gave the lowest number of PSMs. Interestingly however, these marked differences tended to normalize when the median sequence coverages of matrisome proteins (Fig. 2C) were considered. Median sequence coverages ranged from $13 \%$ to $20 \%$ with the lowest value obtained for the insoluble fraction of the compartmental protocol and the highest value for the insoluble fraction of the chemical decellularization method.

Finally, in all protocols, the total number of matrisome proteins identified in the insoluble fractions was comparatively lower than in other fractions (Supplementary Fig. 2-5), suggesting that the analysis of the more soluble fractions provide significant added-value in terms of matrisome coverage, as further discussed below.

The skin associated matrisome is better covered through ECM enrichment and requires extraction in less stringent buffers

ECM enrichment protocols all led to the same distribution of proteins between the core (around $40 \%$ ) and associated (around $60 \%$ ) matrisomes (Fig. 3). However, the proportion of associated matrisome components decreased to $50 \%$ in the total skin lysate, suggesting that the latter approach was less efficient to reveal lower-abundance ECM components. Furthermore, a similar distribution of proteins 
among the 6 matrisome subcategories was observed for all enrichment methods while a substantially lower content in secreted factors was obtained with the total skin lysate. Inversely, collagens were enriched in the total skin lysate and represented $18 \%$ of the matrisome proteins, to be compared with a mean value of $13 \%$ for enrichment protocols. These results indicated that skin processing through total lysis led to samples which were too complex to allow in-depth identification of matrisome components by MS/MS.

The reproducibility of ECM enrichment protocols was also evaluated by comparing the results obtained from three biological replicates corresponding to skin samples originating from three different mice. A total of 188, 173 and 200 matrisome components was detected in the three mice and 145 proteins were common to all animals (Fig. 4A). The distribution of all identified proteins between the core and associated matrisome categories was then characterized in each fraction of the four enrichment protocols for the three mice. In total, 11 fractions were characterized for the three mice in addition to the total lysates (Fig. 1). The $\mathrm{NaCl}$ fractions of the chemical and enzymatic decellularization methods being identical, only one of two collected fractions was analyzed by MS/MS. The number of core matrisome proteins varied substantially in the various extraction fractions of the three mice (between 19 and 63) and was 49 or 69 for the two skin samples analyzed as total lysates (Fig. 4B). For all enrichment protocols, the highest inter-individual variability was systematically observed in the first steps of tissue processing, suggesting that the most labile ECM core components are more easily lost and difficult to recover in a reproducible manner.

Interestingly, the core matrisome proteins which could have been expected to be enriched in high stringency buffers due to their low solubility were also found in high numbers in the first extraction fractions (Fig. 4B), as confirmed by the detailed analysis of fraction content (Supplementary Table 2). This finding suggests that core matrisome proteins show a wide range of solubilities depending on their interactions with other ECM components or on their maturation levels. Indeed, several core matrisome components undergo extracellular maturations, which are known to affect their solubility. Prototypical examples are the fibrillar collagens (mainly I, III and V in skin) which are secreted as soluble precursor molecules and cannot form fibrils before the proteolytic removal of their $\mathrm{N}$ - and C-terminal propeptides [43]. The chains of these collagens were identified in all fractions, at least for one of the three mice. Proteolytic maturations also affect collagens VI [44] and VII [45], laminin 332 or the small leucine-rich proteoglycans biglycan, decorin and mimecan [46] which were well distributed among extraction fractions. The exception is the $\gamma 2$ chain of laminin 332 (Lamc2), which seemed to be preferably extracted in the less soluble skin compartments. In agreement with this observation, all the peptides identified for this laminin chain corresponded to the mature form. More generally, proteolysis is known to play a major role to regulate the interaction properties of ECM proteins. For example, thrombospondin-1 was exclusively identified in low stringency buffers with peptides belonging to its $\mathrm{N}$-terminal domain and it is known that thrombospondins lose their ability to form oligomers and become soluble when they are cleaved at specific sites further in the protein sequence $[47,48]$. Also, small fragments released from core matrisome proteins, also known as matricryptins, can play major signalling functions $[13,49]$ due to their increased solubility, potentially explaining the presence of several collagens, fibronectin, perlecan or elastin in the first extraction fractions of the various protocols.

Regarding the associated matrisome, between 17 and 83 proteins were identified in the 11 enrichment fractions and, in contrast to the results obtained with the core matrisome, there was a clear decrease in protein recovery with the progression of the four protocols towards more stringent buffers (Fig. 4C). Strikingly, for all protocols, the insoluble fraction had the lowest number of identified proteins while the first extraction of each protocol was the most efficient to enrich associated matrisome. For 
example, with the QDSP protocol, which has been specifically designed for protein solubility profiling, mean numbers of $63,60,49$ and 27 proteins were recovered with buffer 1 combined with PBS, buffer 2 , buffer 3 and in insoluble pellet respectively. This corresponds well to the solubility profile expected for the associated matrisome, with a high content in enzymes and signaling molecules, which are potentially less tightly bound to the matrix than core matrisome components. Still, some associated matrisome components were also found in the final insoluble fractions such as annexins, cystatins, galectins or plasminogen (Supplementary Table 2). Also, the cross-linking enzyme lysyl oxidase homolog-1 and the tissue inhibitor of matrix metalloproteinase 3 (TIMP-3) were only found in insoluble fractions.

Core matrisome components are quantitatively more stable between individuals and protocols than associated matrisome components

For all enrichment fractions, the high similarity in the identity of core matrisome components observed between replicates suggests a highly stable composition in skin structural ECM proteins (Fig. 4B). In contrast, the composition of the associated matrisome showed more marked differences between replicates (Fig. 4C). This was observed for all enrichment protocols with the most pronounced differences in the insoluble fractions. This suggests that the low abundance of associated matrisome components makes their detection more challenging and less reproducible or that these components are more likely to undergo individual-specific modulations due to their regulatory functions.

To confirm this qualitative trend and assess the compatibility of ECM enrichment protocols with quantitative analysis, we compared the abundance of matrisome proteins in the insoluble fractions of the three mice (Fig. 5, Supplementary Fig. 6 and Supplementary Table 3). All tested methods give coherent abundance values for core matrisome proteins, both when replicates are compared and when methods are compared. As expected, collagens appear as the most abundant components in the insoluble compartment of skin samples followed by proteoglycans and then by glycoproteins which are globally less abundant. It is also in the glycoprotein group that the variability between individuals is most pronounced, a trend which is further exacerbated in the associated matrisome (Supplementary Fig. 6). Therefore, abundance results confirm the observations made above. They also suggest that ECM enrichment protocols should be amenable to relative quantification if several types of skin samples are to be compared.

The matrisome of healthy adult mouse skin comprises 95 core matrisome proteins and 141 associated matrisome proteins

All the data obtained with the four enrichment protocols and the total lysates were finally combined to generate a list of proteins defining the mouse skin matrisome in homeostasis conditions (Tables 2 and 3). Among the 1112 components presently described in the mouse matrisome (http://matrisomeproject.mit.edu/), 236 were identified in the skin of healthy adult mice ( $21 \%$ of all matrisome content). These comprised 308 proteoforms, with some redundancy due to protein isoforms and variants (Supplementary Table 2).

Ninety-five core matrisome proteins were detected in our experiments, among which 30 are collagen chains ( $68 \%$ of all collagen chains), 53 are glycoproteins ( $27 \%$ of core matrisome glycoproteins) and 12 are proteoglycans (33\% of core matrisome proteoglycans) (Table 2). Among collagens, some of them are well-described skin components such as collagens I, III, V, VI, XII and XIV found in the dermis, 
collagens XV and XVI in the dermis and DEJ, collagens IV, VII, XVII and XVIII in the DEJ $[3,6,50]$. Collagen XIII, a normal component of the epidermis and DEJ was not detected, possibly because of its cellmembrane localization and the fact that most protocols were not designed to efficiently retrieve membrane proteins. Interestingly also, seven additional collagen chains were observed. Among them, the presence of fibrillar collagens II and XI was particularly surprising because these molecules have mainly been reported in cartilage and vitreous body [43,51]. However, they were also identified by LCMS/MS in decellularized human skin [28] and could be low-abundance collagens of normal skin. Collagen XXVII is also found in adult cartilage and in fetal dermis [52]. Collagen XX remains poorly characterized in terms of tissue distribution and functions, but its expression is currently supposed to be limited to fetal life [53]. Collagen XXVIII [54] as well as transmembrane collagen XXV [55] are commonly associated to the nervous system and their presence could be explained by the presence of nerve endings in skin.

As lysine hydroxylation is a well-known modification of collagens, we also tested whether adding "lysine oxidation" as variable modification could impact collagen detection in the insoluble fractions of all protocols. This led to the identification of two additional collagens, collagen XXII (one peptide identified in the three mice with all protocols except QDSP) and collagen XXIII (one peptide identified in one mouse with the chemical decellularization protocol) (Supplementary Table 4). Besides, oxidized Iysine residues could be attributed to around $15 \%$ of unique peptides in fibrillar collagens I, II, III and $\mathrm{V}$ and were also found in collagens IV ( $\alpha 1-\alpha 3), \mathrm{VI}(\alpha 2)$, VII and XVI with more variability. However, the inclusion of this modification had a rather modest effect on the total number of unique peptides identified for these insoluble collagens (less than $10 \%$ on average). Moreover, some proteins for which this modification has not been previously reported seem to be incorrectly identified as carrying oxidized lysines, both among matrisome (biglycan and serpinb6a; Supplementary Table 4) and nonmatrisome components (e.g. keratins 6 a and 13, myosins 1 and 4, nebulin). Therefore, we chose not to include this modification systematically.

Regarding the glycoproteins and proteoglycans identified in mouse skin, the key components of the dermal compartment $[4,8,56]$ such as fibronectin, elastin and its partners in elastic fibers (fibrillin-1, fibulins 2 and 5, microfibrillar associated proteins 2,4 and 5 and latent TGF- $\beta$ binding protein 4), smallleucine rich proteoglycans (asporin, biglycan, decorin, dermatopontin, fibromodulin, lumican, mimecan, PRELP and podocan) as well as numerous proteins known to regulate ECM organization and cell-matrix interactions (e.g. SPARC, tenascins $C$ and $X$, thrombospondin- 1 , TGF- $\beta$-induced protein/BIGH3, procollagen C-proteinase enhancer-1) were detected. The DEJ is also very well represented at the level of glycoproteins and proteoglycans $[57,58]$ with all chains of laminins 332 and 511, nidogens 1 and 2 and perlecan being identified with most ECM enrichment protocols (laminin alpha 4 is also found but is more specific to vascular basement membranes). This suggests that our skin preparations are well adapted to study specific processes affecting the DEJ and that there is no need to separate the dermis from the epidermis to obtain a good coverage of the skin structural ECM components. It should also be noted here that a possible optimization applicable to all methods, especially if accurate quantification of proteoglycans and glycoproteins is desired, would be to combine several deglycosylation enzymes (in addition to the classical PNGaseF) to remove glycosaminoglycan (GAG) chains and other O-glycosylations, as described by others [32]. However, the systematic integration of a GAG removal step in ECM-centered analyses must be validated first as a recent study [37] suggested that it may decrease the number of PSMs for collagens and glycoproteins.

In the associated matrisome, 141 components were detected (Table 3) with the following distribution: 84 ECM regulators, 30 ECM-affiliated and 27 secreted factors. Proteases are important members of the ECM regulators with several cathepsins, prothrombin and coagulation factors $X$ and XII, 
plasminogen, trypsins 1 and 5, ADAM10, MMP-2 and -3. Protease inhibitors are also generally well detected with numerous serpins, cystatins, the broad-spectrum inhibitor pregnancy zone protein (or a2-macroglobulin) but only one tissue inhibitor of MMP (TIMP-3). Other enzymes involved in ECM biosynthesis such as prolyl and lysyl hydroxylases and cross-linking enzymes (lysyl oxidase homolog-1 and transglutaminases) are also part of the list but some other prominent players are still missing (procollagen $\mathrm{N}$ - and C-proteinases, lysyl oxidase), possibly due to their low abundance in healthy skin [59].

The category of secreted factors includes some cytokines (CCL27a, IL1 family member 10), growth factors (myostatin, angiopoietin-related proteins 1 and 2), proteins from the epidermal cornified envelope (filaggrins, cornulin, hornerin and repetin) and additional markers of epithelial differentiation (S100 proteins, trichohyalin and trichohyalin-like protein-1) [60,61]. The relative paucity of this matrisome category can be explained by the low expression level of secreted factors in homeostatic conditions, making their detection challenging. Finally, ECM-affiliated proteins are mostly annexins but several proteins normally found at the cell surface (CD209, glypican-1, -4 and -6 , syndecan-4) are also detected, suggesting that their ectodomains can be shed in healthy skin.

When our results on mouse skin are compared to the recent reports describing the matrisome of the healthy human skin dermal compartment (Supplementary Table 5), comparable total numbers of matrisome proteins were detected with a similar enzymatic decellularization method using PLA2 (274 in human when the results of two studies are combined [28,31]). The chemical decellularization method was also used to analyze human dermal samples [30] and led to the identification of less matrisome proteins (99 annotated human matrisome proteins, Supplementary Table 5) but only the $\mathrm{NaCl}$ and $\mathrm{GuHCl}$ extracts were analyzed and different criteria to define ECM proteins were used, explaining the relatively low number of associated matrisome components found in this list. The most comprehensive description of human skin ECM is however given by the work of Dyring-Andersen and colleagues [62] who provided the first proteomic atlas of four skin layers, the outer epidermis, the inner epidermis, the dermis and the subcutis. Specific ECM enrichment was not the goal of this study but, instead, extensive peptide fractionation allowed the identification of more than 10000 proteins. The matrisome annotation of the proteins found in the epidermal and dermal compartments yields a list of 437 proteins (Supplementary Table 5) with around $38 \%$ of core matrisome proteins (to be compared with $40 \%$ in our mouse study) and $62 \%$ of associated matrisome proteins (60\% in our study). The comparison of our mouse dataset with all these previous studies made on human skin also indicates that about $84 \%$ of the skin matrisome proteins detected in mouse match with the human ones. The differences mainly lie in species-specific genetic variants, especially for the large serpin family [63]. However, there are some differences which could be more significant for skin biology. For example, if the overall number of collagen chains identified is relatively stable between species and studies, some collagen chains are only found in mouse skin (Col9a1, Col11a2, Col20a1) while some other chains are specifically detected in human skin (COL4A4, COL4A6, COL8A1, COL8A2, COL10A1, COL21A1). Whether these differences can substantially impact cutaneous functions remains to be determined.

The rat dermal matrisome was also reported in a previous study [28] but, for unclear reasons, a comparatively low number of 102 matrisome proteins was identified with a poor coverage of the associated matrisome (42 proteins compared to 142 for mouse skin, Supplementary Table 5). Some technical differences in reagent concentrations or sample processing could explain this apparent discrepancy and we expect that the detailed protocols and analyses provided in the present study will help users to set up reproducible and efficient skin ECM enrichment protocols. 


\section{Conclusion}

Our comparison of four ECM enrichment protocols indicates that skin matrisome proteins exhibit diverse solubility profiles and that there is a real benefit in terms of matrisome coverage to analyze some of the liquid extraction fractions, not only the final insoluble pellet. If applied to the comparison of healthy and diseased skins, this could reveal subtle changes in ECM protein solubility, induced by alterations in tissue composition and stiffness/cross-linking, that would have been missed in a more global comparison of total protein amounts. Between the three methods which led to the highest numbers of identified proteins (chemical and enzymatic decellularizations, QDSP), the decellularization methods have the double advantage of requiring a lower number of MS injections compared to QDSP ( 3 instead of 4 ) and of showing a better overall reproducibility when biological replicates are compared. If PLA2 is relatively expensive, it is not the case for the reagents used in the chemical decellularization method that we recommend for routine matrisome characterizations. Importantly, this work also enabled us to report the first comprehensive description of the mouse skin matrisome. Two hundred and thirty-six matrisome proteins were detected, including the main structural components of skin ECM and several associated factors, with $84 \%$ of these components which were also found in the human skin matrisome showing a good conservation between the two species. This work provides a strong basis for the future description of ECM (dys)regulations occurring in skin upon challenge or in various disease contexts.

\section{References}

[1] E. Proksch, J. M. Brandner, J. M. Jensen (2008). The skin: an indispensable barrier. Exp Dermatol. 17, 1063-1072. https://doi.org/10.1111/j.1600-0625.2008.00786.x.

[2] D. Breitkreutz, N. Mirancea, R. Nischt (2009). Basement membranes in skin: unique matrix structures with diverse functions? Histochem Cell Biol. 132, 1-10. https://doi.org/10.1007/s00418-009-0586-0.

[3] E. Roig-Rosello, P. Rousselle (2020). The Human Epidermal Basement Membrane: A Shaped and Cell Instructive Platform That Aging Slowly Alters. Biomolecules. 10, 1607. https://doi.org/10.3390/biom10121607.

[4] T. Krieg, M. Aumailley (2011). The extracellular matrix of the dermis: flexible structures with dynamic functions. Exp Dermatol. 20, 689-695. https://doi.org/10.1111/j.16000625.2011.01313.x.

[5] J. Myllyharju, K. I. Kivirikko (2004). Collagens, modifying enzymes and their mutations in humans, flies and worms. Trends Genet. 20, 33-43. https://doi.org/10.1016/j.tig.2003.11.004.

[6] S. Ricard-Blum (2011). The collagen family. Cold Spring Harb Perspect Biol. 3, a004978. https://doi.org/10.1101/cshperspect.a004978.

[7] R. V. Iozzo, L. Schaefer (2015). Proteoglycan form and function: A comprehensive $\begin{array}{llll}\text { nomenclature of proteoglycans. Matrix Biol. 42, 11-55. } & \text {. }\end{array}$ https://doi.org/10.1016/j.matbio.2015.02.003.

[8] A. Nystrom, L. Bruckner-Tuderman (2019). Matrix molecules and skin biology. Semin Cell Dev Biol. 89, 136-146. https://doi.org/10.1016/i.semcdb.2018.07.025.

[9] G. S. Schultz, A. Wysocki (2009). Interactions between extracellular matrix and growth factors in wound healing. Wound Repair Regen. 17, 153-162. https://doi.org/10.1111/i.1524475X.2009.00466.X.

[10] J. Zeng-Brouwers, S. Pandey, J. Trebicka, M. Wygrecka, L. Schaefer (2020). Communications via the Small Leucine-rich Proteoglycans: Molecular Specificity in Inflammation and Autoimmune Diseases. J Histochem Cytochem. 68, 887-906. https://doi.org/10.1369/0022155420930303. 
[11] J. Halper, M. Kjaer (2014). Basic components of connective tissues and extracellular matrix: elastin, fibrillin, fibulins, fibrinogen, fibronectin, laminin, tenascins and thrombospondins. Adv Exp Med Biol. 802, 31-47. https://doi.org/10.1007/978-94-007-7893-1 3.

[12] N. K. Karamanos, A. D. Theocharis, T. Neill, R. V. Iozzo (2019). Matrix modeling and remodeling: A biological interplay regulating tissue homeostasis and diseases. Matrix Biol. 75-76, 1-11. https://doi.org/10.1016/j.matbio.2018.08.007.

[13] S. Ricard-Blum, S. D. Vallet (2016). Proteases decode the extracellular matrix cryptome. Biochimie. 122, 300-313. https://doi.org/10.1016/j.biochi.2015.09.016.

[14] C. Moali, D. J. Hulmes (2009). Extracellular and cell surface proteases in wound healing: new players are still emerging. Eur J Dermatol. 19, 552-564. https://doi.org/10.1684/ejd.2009.0770.

[15] J. Filmus, M. Capurro, J. Rast (2008). Glypicans. Genome Biol. 9, 224. https://doi.org/10.1186/gb-2008-9-5-224.

[16] S. Mii, A. Enomoto, Y. Shiraki, T. Taki, Y. Murakumo, M. Takahashi (2019). CD109: a multifunctional GPI-anchored protein with key roles in tumor progression and physiological homeostasis. Pathol Int. 69, 249-259. https://doi.org/10.1111/pin.12798.

[17] J. Weisz, V. N. Uversky (2020). Zooming into the Dark Side of Human Annexin-S100 Complexes: Dynamic Alliance of Flexible Partners. Int J Mol Sci. 21. https://doi.org/10.3390/ijms21165879.

[18] A. Naba, K. R. Clauser, S. Hoersch, H. Liu, S. A. Carr, R. O. Hynes (2012). The matrisome: in silico definition and in vivo characterization by proteomics of normal and tumor extracellular matrices. Mol Cell Proteomics. 11, M111 014647. https://doi.org/10.1074/mcp.M111.014647.

[19] A. Naba, K. R. Clauser, H. Ding, C. A. Whittaker, S. A. Carr, R. O. Hynes (2016). The extracellular matrix: Tools and insights for the "omics" era. Matrix Biol. 49, 10-24. https://doi.org/10.1016/j.matbio.2015.06.003.

[20] A. Naba, K. R. Clauser, R. O. Hynes (2015). Enrichment of Extracellular Matrix Proteins from Tissues and Digestion into Peptides for Mass Spectrometry Analysis. J Vis Exp. e53057. https://doi.org/10.3791/53057.

[21] A. Naba, K. R. Clauser, D. R. Mani, S. A. Carr, R. O. Hynes (2017). Quantitative proteomic profiling of the extracellular matrix of pancreatic islets during the angiogenic switch and insulinoma progression. Sci Rep. 7, 40495. https://doi.org/10.1038/srep40495.

[22] A. Naba, K. R. Clauser, J. M. Lamar, S. A. Carr, R. O. Hynes (2014). Extracellular matrix signatures of human mammary carcinoma identify novel metastasis promoters. Elife. 3, e01308. https://doi.org/10.7554/eLife.01308.

[23] V. Gocheva, A. Naba, A. Bhutkar, T. Guardia, K. M. Miller, C. M. Li, T. L. Dayton, F. J. SanchezRivera, C. Kim-Kiselak, N. Jailkhani, M. M. Winslow, A. Del Rosario, R. O. Hynes, T. Jacks (2017). Quantitative proteomics identify Tenascin- $C$ as a promoter of lung cancer progression and contributor to a signature prognostic of patient survival. Proc Natl Acad Sci U S A. 114, E5625E5634. https://doi.org/10.1073/pnas.1707054114.

[24] A. Naba, K. R. Clauser, C. A. Whittaker, S. A. Carr, K. K. Tanabe, R. O. Hynes (2014). Extracellular matrix signatures of human primary metastatic colon cancers and their metastases to liver. BMC Cancer. 14, 518. https://doi.org/10.1186/1471-2407-14-518.

[25] H. B. Schiller, I. E. Fernandez, G. Burgstaller, C. Schaab, R. A. Scheltema, T. Schwarzmayr, T. M. Strom, O. Eickelberg, M. Mann (2015). Time- and compartment-resolved proteome profiling of the extracellular niche in lung injury and repair. Mol Syst Biol. 11, 819. https://doi.org/10.15252/msb.20156123.

[26] A. Didangelos, X. Yin, K. Mandal, M. Baumert, M. Jahangiri, M. Mayr (2010). Proteomics characterization of extracellular space components in the human aorta. Mol Cell Proteomics. 9, 2048-2062. https://doi.org/10.1074/mcp.M110.001693.

[27] A. E. Mayorca-Guiliani, C. D. Madsen, T. R. Cox, E. R. Horton, F. A. Venning, J. T. Erler (2017). ISDoT: in situ decellularization of tissues for high-resolution imaging and proteomic analysis of native extracellular matrix. Nat Med. 23, 890-898. https://doi.org/10.1038/nm.4352. 
[28] B. Liu, S. Zhang, W. Wang, Z. Yun, L. Lv, M. Chai, Z. Wu, Y. Zhu, J. Ma, L. Leng (2020). Matrisome Provides a Supportive Microenvironment for Skin Functions of Diverse Species. ACS Biomater Sci Eng. 6, 5720-5733. https://doi.org/10.1021/acsbiomaterials.0c00479.

[29] M. Dussoyer, A. Michopoulou, P. Rousselle (2020). Decellularized scaffolds for skin repair and regeneration. Appl Sci. 10, 3435. https://doi.org/10.3390/app10103435.

[30] J. Barallobre-Barreiro, E. Woods, R. E. Bell, J. A. Easton, C. Hobbs, M. Eager, F. Baig, A. M. Ross, R. Mallipeddi, B. Powell, M. Soldin, M. Mayr, T. J. Shaw (2019). Cartilage-like composition of keloid scar extracellular matrix suggests fibroblast mis-differentiation in disease. Matrix Biol Plus. 4, 100016. https://doi.org/10.1016/i.mbplus.2019.100016.

[31] S. Zhang, B. Liu, W. Wang, L. Lv, D. Gao, M. Chai, M. Li, Z. Wu, Y. Zhu, J. Ma, L. Leng (2021). The "Matrisome" reveals the characterization of skin keloid microenvironment. FASEB J. 35, e21237. https://doi.org/10.1096/fj.202001660RR.

[32] J. Barallobre-Barreiro, F. Baig, M. Fava, X. Yin, M. Mayr (2017). Glycoproteomics of the Extracellular Matrix: A Method for Intact Glycopeptide Analysis Using Mass Spectrometry. J Vis Exp. 55674. https://doi.org/10.3791/55674.

[33] C. W. Wong, C. F. LeGrand, B. F. Kinnear, R. M. Sobota, R. Ramalingam, D. E. Dye, M. Raghunath, E. B. Lane, D. R. Coombe (2019). In Vitro Expansion of Keratinocytes on Human Dermal Fibroblast-Derived Matrix Retains Their Stem-Like Characteristics. Sci Rep. 9, 18561. https://doi.org/10.1038/s41598-019-54793-9.

[34] Z. Wu, Y. Zhou, N. Li, M. Huang, H. Duan, J. Ge, P. Xiang, Z. Wang (2009). The use of phospholipase $\mathrm{A}(2)$ to prepare acellular porcine corneal stroma as a tissue engineering scaffold. Biomaterials. 30, 3513-3522. https://doi.org/10.1016/i.biomaterials.2009.03.003.

[35] Y. Perez-Riverol, A. Csordas, J. Bai, M. Bernal-Llinares, S. Hewapathirana, D. J. Kundu, A. Inuganti, J. Griss, G. Mayer, M. Eisenacher, E. Perez, J. Uszkoreit, J. Pfeuffer, T. Sachsenberg, S. Yilmaz, S. Tiwary, J. Cox, E. Audain, M. Walzer, A. F. Jarnuczak, T. Ternent, A. Brazma, J. A. Vizcaino (2019). The PRIDE database and related tools and resources in 2019: improving support for quantification data. Nucleic Acids Res. 47, D442-D450. https://doi.org/10.1093/nar/gky1106.

[36] L. Nguyen, V. Brun, F. Combes, V. Loux, Y. Vandenbrouck (2019). Designing an In Silico Strategy to Select Tissue-Leakage Biomarkers Using the Galaxy Framework. Methods Mol Biol. 1959, 275-289. https://doi.org/10.1007/978-1-4939-9164-8 18.

[37] M. C. McCabe, L. R. Schmitt, R. C. Hill, M. Dzieciatkowska, M. Maslanka, W. F. Daamen, T. H. van Kuppevelt, D. J. Hof, K. C. Hansen (2021). Evaluation and Refinement of Sample Preparation Methods for Extracellular Matrix Proteome Coverage. Mol Cell Proteomics. 20, 100079. https://doi.org/10.1016/i.mcpro.2021.100079.

[38] J. Barallobre-Barreiro, A. Didangelos, F. A. Schoendube, I. Drozdov, X. Yin, M. FernandezCaggiano, P. Willeit, V. O. Puntmann, G. Aldama-Lopez, A. M. Shah, N. Domenech, M. Mayr (2012). Proteomics analysis of cardiac extracellular matrix remodeling in a porcine model of ischemia/reperfusion injury. Circulation. 125, 789-802. https://doi.org/10.1161/CIRCULATIONAHA.111.056952.

[39] J. Barallobre-Barreiro, R. Oklu, M. Lynch, M. Fava, F. Baig, X. Yin, T. Barwari, D. N. Potier, H. Albadawi, M. Jahangiri, K. E. Porter, M. T. Watkins, S. Misra, J. Stoughton, M. Mayr (2016). Extracellular matrix remodelling in response to venous hypertension: proteomics of human varicose veins. Cardiovasc Res. 110, 419-430. https://doi.org/10.1093/cvr/cvw075.

[40] L. E. de Castro Bras, T. A. Ramirez, K. Y. DeLeon-Pennell, Y. A. Chiao, Y. Ma, Q. Dai, G. V. Halade, K. Hakala, S. T. Weintraub, M. L. Lindsey (2013). Texas 3-step decellularization protocol: looking at the cardiac extracellular matrix. J Proteomics. 86, 43-52. https://doi.org/10.1016/i.jprot.2013.05.004.

[41] L. Mayer, R. Pechlaner, J. Barallobre-Barreiro, C. Boehme, T. Toell, M. Lynch, X. Yin, J. Willeit, E. R. Gizewski, P. Perco, G. Ratzinger, S. Kiechl, M. Mayr, M. Knoflach (2020). Extracellular matrix protein signature of recurrent spontaneous cervical artery dissection. Neurology. 95, e2047-e2055. https://doi.org/10.1212/WNL.0000000000010710. 
[42] J. Kjell, J. Fischer-Sternjak, A. J. Thompson, C. Friess, M. J. Sticco, F. Salinas, J. Cox, D. C. Martinelli, J. Ninkovic, K. Franze, H. B. Schiller, M. Gotz (2020). Defining the Adult Neural Stem Cell Niche Proteome Identifies Key Regulators of Adult Neurogenesis. Cell Stem Cell. 26, 277293 e278. https://doi.org/10.1016/i.stem.2020.01.002.

[43] J. Bella, D. J. Hulmes (2017). Fibrillar Collagens. Subcell Biochem. 82, 457-490. https://doi.org/10.1007/978-3-319-49674-0 14.

[44] S. E. Heumuller, M. Talantikite, M. Napoli, J. Armengaud, M. Morgelin, U. Hartmann, G. Sengle, M. Paulsson, C. Moali, R. Wagener (2019). C-terminal proteolysis of the collagen VI alpha3 chain by BMP-1 and proprotein convertase(s) releases endotrophin in fragments of different sizes. J Biol Chem. 294, 13769-13780. https://doi.org/10.1074/jbc.RA119.008641.

[45] A. Rattenholl, W. N. Pappano, M. Koch, D. R. Keene, K. E. Kadler, T. Sasaki, R. Timpl, R. E. Burgeson, D. S. Greenspan, L. Bruckner-Tuderman (2002). Proteinases of the bone morphogenetic protein-1 family convert procollagen VII to mature anchoring fibril collagen. J Biol Chem. 277, 26372-26378. https://doi.org/10.1074/ibc.M203247200.

[46] S. Vadon-Le Goff, D. J. Hulmes, C. Moali (2015). BMP-1/tolloid-like proteinases synchronize matrix assembly with growth factor activation to promote morphogenesis and tissue remodeling. Matrix Biol. 44-46, 14-23. https://doi.org/10.1016/j.matbio.2015.02.006.

[47] C. Anastasi, P. Rousselle, M. Talantikite, A. Tessier, C. Cluzel, A. Bachmann, N. Mariano, M. Dussoyer, L. B. Alcaraz, L. Fortin, A. Aubert, F. Delolme, N. El Kholti, J. Armengaud, P. Fournie, C. Auxenfans, U. Valcourt, S. V. Goff, C. Moali (2020). BMP-1 disrupts cell adhesion and enhances TGF-beta activation through cleavage of the matricellular protein thrombospondin1. Sci Signal. 13, eaba3880. https://doi.org/10.1126/scisignal.aba3880.

[48] D. J. Kim, E. D. Christofidou, D. R. Keene, M. Hassan Milde, J. C. Adams (2015). Intermolecular interactions of thrombospondins drive their accumulation in extracellular matrix. Mol Biol Cell. 26, 2640-2654. https://doi.org/10.1091/mbc.E14-05-0996.

[49] A. G. Marneros, B. R. Olsen (2001). The role of collagen-derived proteolytic fragments in angiogenesis. Matrix Biol. 20, 337-345. https://doi.org/10.1016/s0945-053x(01)00151-2.

[50] G. Theocharidis, J. T. Connelly (2019). Minor collagens of the skin with not so minor functions. J Anat. 235, 418-429. https://doi.org/10.1111/joa.12584.

[51] D. Eyre (2002). Collagen of articular cartilage. Arthritis Res. 4, 30-35. https://doi.org/10.1186/ar380.

[52] D. A. Plumb, V. Dhir, A. Mironov, L. Ferrara, R. Poulsom, K. E. Kadler, D. J. Thornton, M. D. Briggs, R. P. Boot-Handford (2007). Collagen XXVII is developmentally regulated and forms thin fibrillar structures distinct from those of classical vertebrate fibrillar collagens. J Biol Chem. 282, 12791-12795. https://doi.org/10.1074/jbc.C700021200.

[53] M. Koch, J. E. Foley, R. Hahn, P. Zhou, R. E. Burgeson, D. R. Gerecke, M. K. Gordon (2001). alpha $1(X X)$ collagen, a new member of the collagen subfamily, fibril-associated collagens with interrupted triple helices. J Biol Chem. 276, 23120-23126. https://doi.org/10.1074/ibc.M009912200.

[54] S. Grimal, S. Puech, R. Wagener, S. Venteo, P. Carroll, A. Fichard-Carroll (2010). Collagen XXVIII is a distinctive component of the peripheral nervous system nodes of ranvier and surrounds nonmyelinating glial cells. Glia. 58, 1977-1987. https://doi.org/10.1002/glia.21066.

[55] T. Wakabayashi (2020). Transmembrane Collagens in Neuromuscular Development and Disorders. Front Mol Neurosci. 13, 635375. https://doi.org/10.3389/fnmol.2020.635375.

[56] J. Dengjel, L. Bruckner-Tuderman, A. Nystrom (2020). Skin proteomics - analysis of the extracellular matrix in health and disease. Expert Rev Proteomics. 17, 377-391. https://doi.org/10.1080/14789450.2020.1773261.

[57] D. Breitkreutz, I. Koxholt, K. Thiemann, R. Nischt (2013). Skin basement membrane: the foundation of epidermal integrity--BM functions and diverse roles of bridging molecules nidogen and perlecan. Biomed Res Int. 2013, 179784. https://doi.org/10.1155/2013/179784.

[58] C. Has, A. Nystrom (2015). Epidermal Basement Membrane in Health and Disease. Curr Top Membr. 76, 117-170. https://doi.org/10.1016/bs.ctm.2015.05.003. 
[59] P. C. Trackman (2005). Diverse biological functions of extracellular collagen processing enzymes. J Cell Biochem. 96, 927-937. https://doi.org/10.1002/jcb.20605.

[60] W. Lesniak, A. Graczyk-Jarzynka (2015). The S100 proteins in epidermis: Topology and function. Biochim Biophys Acta. 1850, 2563-2572. https://doi.org/10.1016/i.bbagen.2015.09.015.

[61] A. Sandilands, C. Sutherland, A. D. Irvine, W. H. McLean (2009). Filaggrin in the frontline: role in skin barrier function and disease. J Cell Sci. 122, 1285-1294. https://doi.org/10.1242/ics.033969.

[62] B. Dyring-Andersen, M. B. Lovendorf, F. Coscia, A. Santos, L. B. P. Moller, A. R. Colaco, L. Niu, M. Bzorek, S. Doll, J. L. Andersen, R. A. Clark, L. Skov, M. B. M. Teunissen, M. Mann (2020). Spatially and cell-type resolved quantitative proteomic atlas of healthy human skin. Nat Commun. 11, 5587. https://doi.org/10.1038/s41467-020-19383-8.

[63] C. Heit, B. C. Jackson, M. McAndrews, M. W. Wright, D. C. Thompson, G. A. Silverman, D. W. Nebert, V. Vasiliou (2013). Update of the human and mouse SERPIN gene superfamily. Hum Genomics. 7, 22. https://doi.org/10.1186/1479-7364-7-22. 
Figure 1. Overview of the steps and buffers used for tissue processing in selected ECM enrichment protocols. The colored circles indicate fractions that were analyzed by MS/MS.

Figure 2. Comparison of the matrisome content identified with the four enrichment protocols. A: Venn diagram of matrisome proteins detected with the four methods (the diagram including total lysates is available in Supplementary Figure 1). B: Cumulative PSM counts for matrisome proteins (shown as a sum of individual fractions). C: Median sequence coverage for matrisome proteins. All bar plots represent means with SD ( $n=3$ mice). Ins = Insoluble fraction.

Figure 3. Percentage of the matrisome subcategories detected in mouse skin using the enrichment protocols and the total lysate approach.

Figure 4. Matrisome protein distribution in the biological replicates and extraction fractions. A: Global comparison of matrisome proteins detected in the biological replicates. B: Core matrisome proteins identified in the extraction fractions analyzed by MS/MS and in total lysates. C: Associated matrisome proteins identified in the extraction fractions analyzed by MS/MS and in the total lysates. The percentage of proteins detected in at least two replicates is indicated by numbers above the bars for each fraction. The $\mathrm{NaCl}$ fraction is the same for the chemical and enzymatic decellularizations but was represented twice to give a complete overview of the various protocols. Ins = Insoluble fraction.

Figure 5. Heatmap representation of the abundance of core matrisome proteins in the insoluble fractions of ECM enrichment protocols. Empty rectangles indicate proteins which were detected but could not be quantified.

Supplementary Figure 1. Venn diagram of the matrisome proteins detected with the four enrichment protocols and the total tissue lysates.

Supplementary Figure 2. Venn diagram comparing the matrisome proteins detected in the two analyzed fractions of the compartmental enrichment protocol.

Supplementary Figure 3. Venn diagram comparing the matrisome proteins detected in the three analyzed fractions of the chemical decellularization protocol.

Supplementary Figure 4. Venn diagram comparing the matrisome proteins detected in the three analyzed fractions of the enzymatic decellularization protocol.

Supplementary Figure 5. Venn diagram comparing the matrisome proteins detected in the four analyzed fractions of the QDSP protocol.

Supplementary Figure 6. Heatmap representation of the abundance of associated matrisome proteins in the insoluble fractions of ECM enrichment protocols. Empty rectangles indicate proteins which were detected but could not be quantified. 
Table 1. Overview of protein numbers identified in enrichment protocols and total lysates. The data obtained with three mice were pooled to analyze the numbers of total and matrisome-related proteins identified for each protocol.

\begin{tabular}{|c|c|c|c|c|c|}
\hline & $\begin{array}{c}\text { Compartmental } \\
\text { enrichment }\end{array}$ & $\begin{array}{c}\text { Chemical } \\
\text { decellularization }\end{array}$ & $\begin{array}{c}\text { Enzymatic } \\
\text { decellularization }\end{array}$ & QDSP & Total lysate \\
\hline Principle & $\begin{array}{l}\text { Protein fractionation } \\
\text { of specific cell } \\
\text { compartments }\end{array}$ & $\begin{array}{c}\text { Progressive } \\
\text { decellularization using } \\
\text { SDS, SD, Triton X-100 }\end{array}$ & $\begin{array}{c}\text { Decellularization } \\
\text { using PLA2 } \\
\text { and SD }\end{array}$ & $\begin{array}{l}\text { Protein fractionation } \\
\text { depending on solu- } \\
\text { bility in detergents }\end{array}$ & $\begin{array}{l}\text { Total tissue } \\
\text { lysis in SDS }\end{array}$ \\
\hline Total proteins & 2091 & 2703 & 2596 & 2341 & 1107 \\
\hline Matrisome proteins, including: & 161 & 202 & 201 & 201 & 122 \\
\hline Core matrisome & $38.9 \%$ & $42.1 \%$ & $41.3 \%$ & $41.0 \%$ & $50.8 \%$ \\
\hline Associated matrisome & $61.1 \%$ & $57.9 \%$ & $58.7 \%$ & $59.0 \%$ & $49.2 \%$ \\
\hline $\begin{array}{l}\% \text { of matrisome proteins found in at } \\
\text { least } 2 \text { biological replicates }\end{array}$ & $74.5 \%$ & $73.8 \%$ & $74.7 \%$ & $69.5 \%$ & $66.4 \%$ \\
\hline
\end{tabular}


Table 2. Core matrisome components detected in mouse skin. Numbers of proteins are specified in parentheses for each subcategory of core matrisome components. *: two mouse gene names ( $\operatorname{Tn} x$ and $T n \times b)$ are associated with tenascin- $X$ in the Uniprot database. Tnxb was kept and used for all tenascin$X$ proteoforms. " indicates genes for which only unreviewed protein sequences are available in Uniprot database.

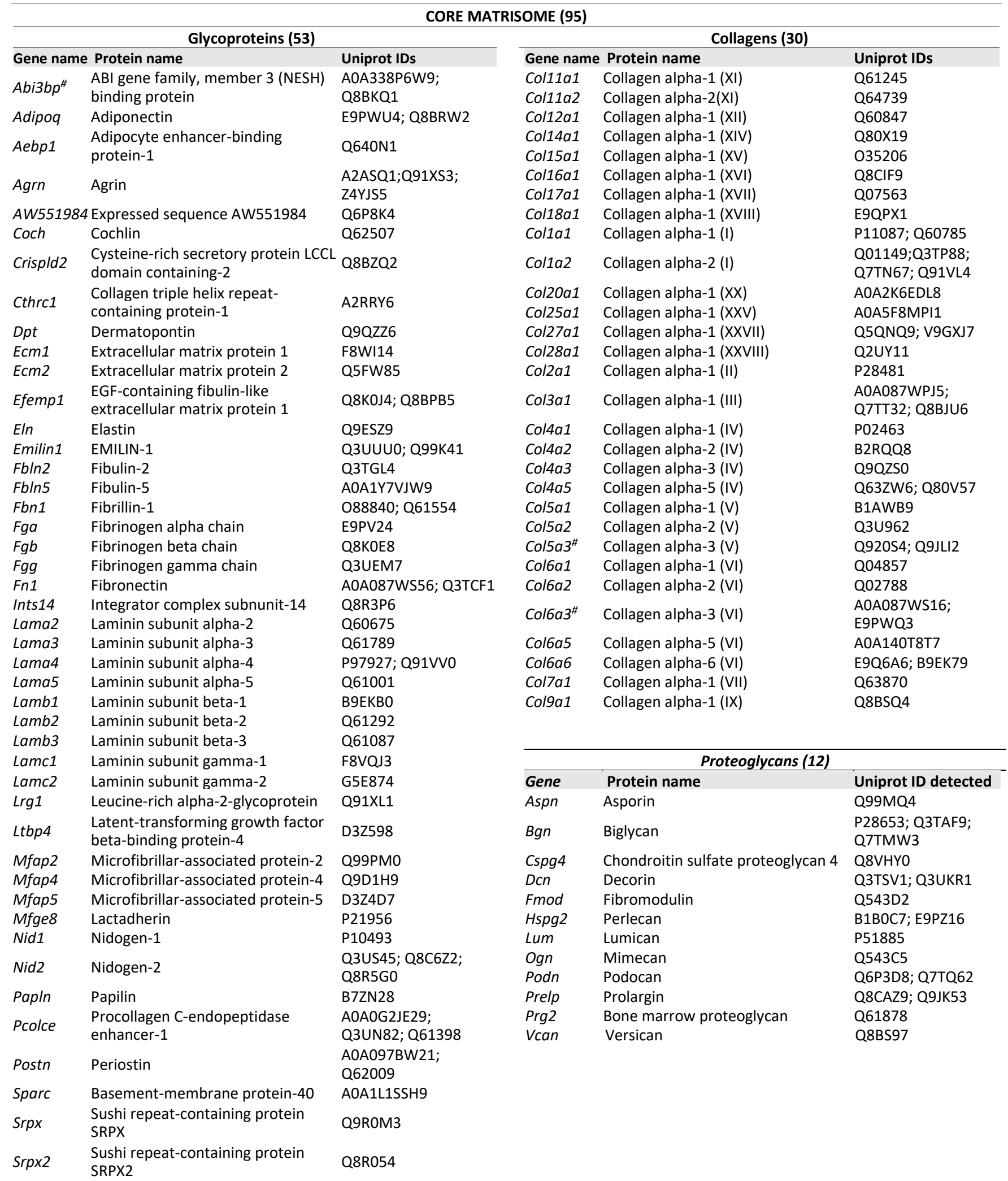


Tgfbi

Thbs1

Tinagl1

Tnc

$\operatorname{Tn} \times b^{* / \#}$

Vtn

Vwa1

Vwa5a
Transforming growth factor-beta- A1L353; Q3UBG4 ;

induced protein ig-h3

Q3TAY9

Q3TR40

hrombospondin-1

Q4FJX7

like

Tenascin-C

Q80YX1

A0A5F8MPH8;

O35452; 054796

P29788

Q8R2Z5

Von Willebrand factor A domain-

containing protein-1

Von Willebrand factor A domain-

containing protein-5A 
Table 3. Associated matrisome components detected in mouse skin. Numbers of proteins are specified in parentheses for each subcategory of associated matrisome components. " indicates genes for which only unreviewed protein sequences are available in Uniprot database.

\begin{tabular}{|c|c|c|c|c|c|}
\hline \multicolumn{6}{|c|}{ ASSOCIATED MATRISOME (141) } \\
\hline \multicolumn{6}{|c|}{ ECM regulators (84) } \\
\hline \multicolumn{2}{|c|}{ Gene name Protein name } & \multirow{2}{*}{$\begin{array}{l}\text { Uniprot ID detected } \\
\text { O35598 }\end{array}$} & \multicolumn{2}{|c|}{ Gene name Protein name } & \multirow{2}{*}{$\begin{array}{l}\text { Uniprot ID detected } \\
\text { Q9Z1R9 }\end{array}$} \\
\hline Adam10 & ADAM10 & & Prss1 ${ }^{\#}$ & Trypsin-1 & \\
\hline Adamts $15^{\#}$ & ADAMTS-like protein-5 & D3Z689 & Pzp & Pregnancy zone protein & Q61838 \\
\hline Agt & Angiotensinogen & P11859 & Serpina10 & Serine protease inhibitor $\mathrm{A} 10$ & Q8R121 \\
\hline$A m b p$ & Protein AMBP & Q07456 & Serpina12 & Serine protease inhibitor $\mathrm{A} 12$ & Q6P6M3 \\
\hline$C 7$ & Complement component C7 & D3YXF5 & Serpina1a & Serine protease inhibitor $\mathrm{A} 1 \mathrm{a}$ & P07758 \\
\hline Cd109 & CD109 antigen & A6MDD3 & Serpina1b & Serine protease inhibitor $\mathrm{A} 1 \mathrm{~b}$ & P22599 \\
\hline Cpn2 & Carboxypeptidase $\mathrm{N}$ subunit 2 & Q9DBB9 & & & AOAOR4J \\
\hline Cst6 & Cystatin-6 & Q8K397 & Serpina1c & Serine protease inhibitor A1C & Q00896 \\
\hline Csta & Cystatin-A & P56567 & Serpina1d & Serine protease inhibitor $\mathrm{A} 1 \mathrm{~d}$ & Q00897 \\
\hline Cstb & Cystatin-B & Q62426 & Serpinale & Serine protease inhibitor $\mathrm{A} 1 \mathrm{e}$ & Q00898 \\
\hline Ctsa & Cathepsin A & Q9D2D1 & Serpina $3 b$ & Serine protease inhibitor $A 3 B$ & Q05A44 \\
\hline Ctsb & Cathepsin B & P10605; Q3TC17 & Serpina3g & Serine protease inhibitor A3G & E9Q499; F2Z405; \\
\hline Ctsc & Cathepsin C & Q9DCV1 & & & 0 \\
\hline Ctsd & Cathepsin D & $\begin{array}{l}\text { Q3TXL5; Q3UCW4; } \\
\text { Q8C243 }\end{array}$ & $\begin{array}{l}\text { Serpina3k } \\
\text { Serpina } 3 m\end{array}$ & $\begin{array}{l}\text { Serine protease inhibitor A3K } \\
\text { Serine protease inhibitor A3M }\end{array}$ & $\begin{array}{l}\text { A0A0R4J011; } \\
\text { Q03734 }\end{array}$ \\
\hline Ctse & Cathepsin E & D3Z6T3 & Serpina3n & Serine protease inhibitor $A 3 B$ & G3X8T9 \\
\hline Ctsh & Cathepsin $\mathrm{H}$ & P49935; Q922Q7 & & & Q06770; Q3UKW1; \\
\hline Ctsk & Cathepsin K & Q545T0 & serpin & Serine protease innibitor & Q91VV0; Q91WQ0 \\
\hline Ctsl & Cathepsin L & Q3UWH6 & Serpina 7 & Serine protease inhibitor A7 & Q3UEL9 \\
\hline Ctss & Cathepsin S & Q8BSZ5 & Serpinb11 & Serine protease inhibitor B11 & Q9CQV3 \\
\hline Ctsz & Cathepsin Z & Q9ES94 & Serpinb1a & Serine protease inhibitor $\mathrm{B} 1 \mathrm{a}$ & Q8BK60; Q9D154 \\
\hline F10 & Coagulation factor $\mathrm{X}$ & Q3TBR2 & Serpinb1b & Serine protease inhibitor B1b & Q8VHP7 \\
\hline F12 & Coagulation factor XII & Q80YC5 & Serpinb2 & Serine protease inhibitor B2 & P12388 \\
\hline F13a1 & Coagulation factor XIII A chain & Q3V3W7 & Serpinb5 & Serine protease inhibitor B5 & P70124 \\
\hline $\begin{array}{l}F 13 b \\
F 2\end{array}$ & $\begin{array}{l}\text { Coagulation factor XIII B chain } \\
\text { Prothrombin }\end{array}$ & $\begin{array}{l}\text { Q3UERO } \\
\text { H7BX99 }\end{array}$ & Serpinb6a & Serine protease inhibitor B6a & $\begin{array}{l}\text { F8WIV2; Q3U3L3; } \\
\text { Q4FJQ6 }\end{array}$ \\
\hline Gm5409 & Try10-like trypsinogen & Q7M754 & & & A0A1Y7VLD5; \\
\hline $\mathrm{Hrg}$ & Histidine-rich glycoprotein & A0A0R4J039 & $p^{*}$ & $36 \mathrm{~b}$ & 008804 \\
\hline & Inter-alpha-trypsin inhibitor & & Serpinb6c $c^{\#}$ & ${ }^{4}$ Serine protease inhibitor $\mathrm{B} 6 \mathrm{C}$ & W4VSP4 \\
\hline Itih1 & heavy chain $\mathrm{H} 1$ & F8WJ05; Q91WU7 & Serpinb7 & Serine protease inhibitor B7 & D3Z2N5 \\
\hline $1+i h 2$ & Inter-alpha-trypsin inhibitor & & Serpinb8 & Serine protease inhibitor B8 & O08800; Q3UFM1 \\
\hline & heavy chain $\mathrm{H} 2$ & & Serpinb9\# & Serine protease inhibitor B9 & 008797 \\
\hline $1+i h 3$ & Inter-alpha-trypsin inhibitor & A0A213BRQ3; & Serpinb9c $c^{\#}$ & Serine protease inhibitor B9c & 17HJI5 \\
\hline ItIIS & heavy chain $\mathrm{H} 3$ & Q61704 & Serpinc1 & Serine protease inhibitor $\mathrm{C} 1$ & Q543J5 \\
\hline Itih4 & Inter-alpha-trypsin inhibitor & F90512 & Serpind 1 & Serine protease inhibitor D1 & Q5FW62 \\
\hline & heavy chain $\mathrm{H} 4$ & & Serpinf1 & Serine protease inhibitor F1 & P97298 \\
\hline & Inter-alpha-trypsin inhibitor & & Serpinf2 & Serine protease inhibitor F2 & Q5ND36 \\
\hline Itih5 & heavy chain $\mathrm{H} 5$ & Q8BJD1 & Serping 1 & Serine protease inhibitor G1 & A2ATR8; P97290 \\
\hline Kng1 & Kininogen-1 & O08677; Q7M084 & Serpinh1 & Serine protease inhibitor $\mathrm{H} 1$ & Q8BVU9; Q3TJK3 \\
\hline Loxl1 & Lysyl oxidase homolog-1 & AOAOR4JOQ4 & Serpini2 & Serine protease inhibitor 12 & Q4G0D3 \\
\hline Mmp2 & Matrix metalloproteinase-2 & P33434; Q6GXA5 & St14 & Serine protease-14 & P56677 \\
\hline Mmp3 & Matrix metalloproteinase-3 & Q3UFJ0 & $\operatorname{Tgm} 1$ & Transglutaminase-1 & Q9JLF6 \\
\hline P3h3 & Prolyl 3-hydroxylase 3 & D6RHQ3 & $\operatorname{Tgm} 2$ & Transglutaminase-2 & P21981 \\
\hline PAha & Prolyl 4-hydroxylase subunit & 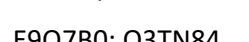 & $\operatorname{Tgm} 3$ & Transglutaminase- 3 & Q08189 \\
\hline P4haI 1 & alpha-1 & E9U/BU; QSIINO4 & $\operatorname{Tgm} 5$ & Transglutaminase- 5 & Q14B90 \\
\hline P4ha2 & Prolyl 4-hydroxylase subunit & & $\operatorname{Tgm}^{\#}$ & Transglutaminase- 6 & Q6YCl4 \\
\hline P4haz & alpha-2 & & Timp3 & Tissue inhibitor of matrix & E9QAB2 \\
\hline$P l g$ & Plasminogen & Q3V1T9 & & & \\
\hline Plod3 & Lysyl hydroxylase-3 & Q3UE11 & Try5 & Trypsin-5 & Q3V2E0 \\
\hline \multicolumn{3}{|c|}{ ECM-affiliated proteins (30) } & \multicolumn{3}{|c|}{ Secreted factors (27) } \\
\hline \multicolumn{2}{|c|}{ Gene name Protein name } & Uniprot ID detected & Gene name & Protein name & Uniprot ID detected \\
\hline Anxa1 & Annexin A1 & Q4FK88 & Angpt/1 & Angiopoietin-related protein-1 & Q640P2 \\
\hline Anxa11 & Annexin A11 & P97384 & Angpt/2 & Angiopoietin-related protein-2 & Q9CZZ8; Q9R045 \\
\hline Anxa2 & Annexin A2 & Q542G9; Q9CZI7 & $C c / 27 a$ & C-C motif chemokine- 27 & A2AMS5 \\
\hline Anxa3 & Annexin A3 & 035639 & $\mathrm{Crnn}^{\#}$ & Cornulin & D3YUU6 \\
\hline Anxa4 & Annexin A4 & P97429; Q7TMN7 & & & \\
\hline Anxa5 & Annexin A5 & P48036 & $\mathrm{Flg}$ & Filaggrin & oYXG4; \\
\hline Anxa6 & Annexin A6 & P14824 & & & \\
\hline
\end{tabular}




\begin{tabular}{|c|c|c|c|c|c|}
\hline Anxa7 & Annexin A7 & Q922A2 & & & C1KG51; Q61571; \\
\hline Anxa8 & Annexin A8 & O35640 & Flg2 & Filaggrin-2 & E9QPZ3; Q2VIS4 \\
\hline Anxa9 & Annexin A9 & Q9JHQ0 & Gm42674 & Predicted gene 42674 & D3YUT9 \\
\hline C1qa & $\begin{array}{l}\text { Complement } \mathrm{C} 1 \mathrm{q} \\
\text { subcomponent subunit } \mathrm{A}\end{array}$ & Q3TXB1 & $\begin{array}{l}\text { Hcfc1 } \\
H r n r\end{array}$ & $\begin{array}{l}\text { Host cell factor-1 } \\
\text { Hornerin }\end{array}$ & $\begin{array}{l}\text { Q3USQ6; Q61191 } \\
\text { E9QNP3 }\end{array}$ \\
\hline$C 1 q b$ & $\begin{array}{l}\text { Complement C1q } \\
\text { subcomponent subunit B }\end{array}$ & Q3U6I5 & $\begin{array}{l}\text { II1f10 } \\
\text { I/1rn }\end{array}$ & $\begin{array}{l}\text { Interleukin-1 family member } 10 \\
\text { Interleukin-1 receptor }\end{array}$ & $\begin{array}{l}\text { Q8R459 } \\
\text { Q542W1; Q8CGA1 }\end{array}$ \\
\hline C1qtnf3 & $\begin{array}{l}\text { Complement C1q tumor } \\
\text { necrosis factor-related protein- }\end{array}$ & D3YZ61 & M6pr & $\begin{array}{l}\text { Cation-dependent mannose-6- } \\
\text { phosphate receptor }\end{array}$ & Q3UF03 \\
\hline$C d 209 b$ & CD209 antigen-like protein B & Q8CJ85 & Mstn & Myostatin & Q3ZAS9 \\
\hline Cd209d & CD209 antigen-like protein D & Q3UW57 & Rptn & Repetin & P97347 \\
\hline Clec10a & C-type lectin domain family-10 & A2CF65 & S100a1 & Protein S100-A1 & Q91V77; Q9JL08 \\
\hline Clec11a & C-type lectin domain family-11 & 088200 & S100a10 & Protein S100-A10 & Q3UF30 \\
\hline Clec3b & Tetranectin & Q8CFZ6 & S100a11 & Protein S100-A11 & P50543 \\
\hline Gpc1 & Glypican-1 & Q3U3U; Q9QZF2 & S100a13 & Protein S100-A13 & P97352 \\
\hline Gpc4 & Glypican-4 & P51655 & S100a14 & Protein S100-A14 & Q9D2Q8 \\
\hline Gpc6 & Glypican-6 & Q8R3X6 & S100a15a & Protein S100-A15 & Q6S5I3 \\
\hline$H p x$ & Hemopexin & Q91X72 & S100a16 & Protein S100-A16 & D3Z2Y6; Q9D708 \\
\hline Lgals1 & Galectin-1 & P16045 & S100a3 & Protein S100-A3 & P62818 \\
\hline Lgals3 & Galectin-3 & Q3V471 & S100a4 & Protein S100-A4 & A0A0G2JGD2 \\
\hline Lgals7 & Galectin-7 & Q9CRB1 & S100a6 & Protein S100-A6 & P14069 \\
\hline Lgalsl & Galectin-related protein & Q8VED9 & $S 100 b$ & Protein S100-B & P50114 \\
\hline Lman1 & Protein ERGIC-53 & Q9D0F3 & $T c h h^{\#}$ & Trichohyalin & AOAOB4J1F9; \\
\hline Plxdc2 & Plexin domain-containing & B1AY86 & & & Q3V203 \\
\hline Plxnb2 & Plexin B2 & B2RXS4 & Tchhl1 & Trichohyalin-like protein-1 & Q9D3P1 \\
\hline Sdc4 & Syndecan-4 & Q3UKZ1 & & & \\
\hline
\end{tabular}


Supplementary Table 1. Lists of proteins and peptides identified with Proteome Discoverer.

2

3 Supplementary Table 2. Matrisome proteins detected in the three biological replicates.

4

5 Supplementary Table 3. Abundance data for matrisome proteins identified in insoluble fractions.

6

7 Supplementary Table 4. Comparison of unique peptide numbers identified for matrisome proteins

8 in insoluble fractions with or without "oxidized lysine" as variable modification.

9

10 Supplementary Table 5. Comparison of human, rat and mouse skin matrisomes. 
Figure 1
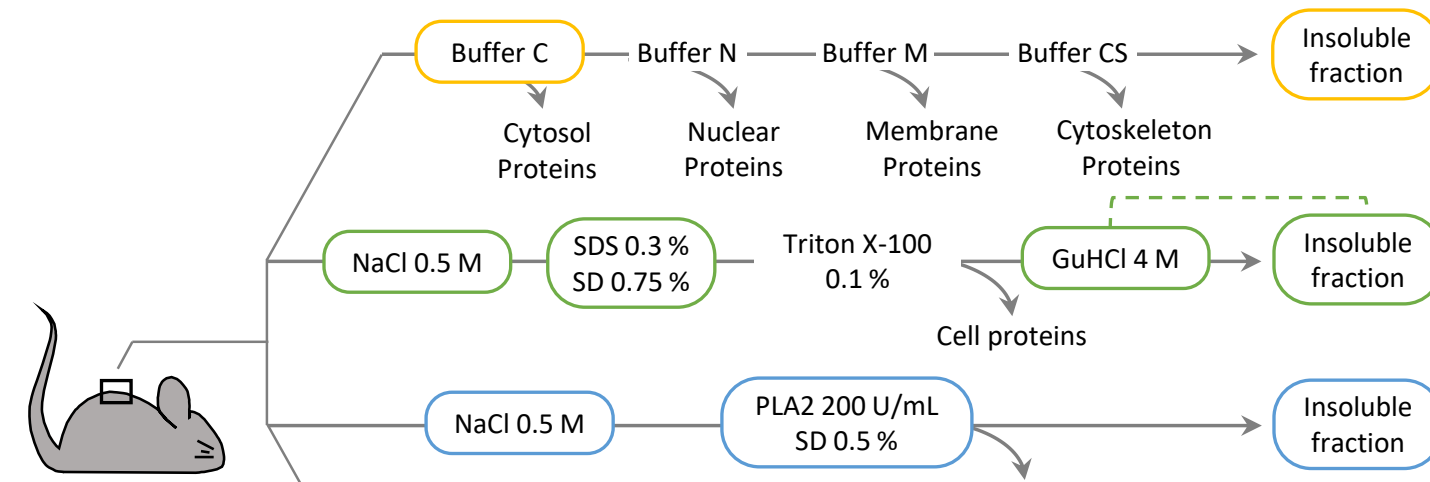

nsoluble

Cytoskeleton

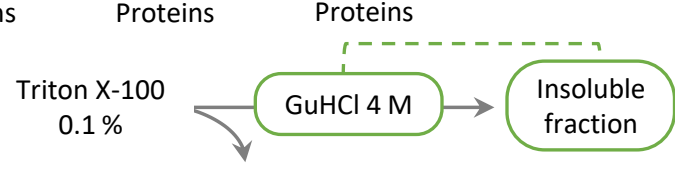

Cell proteins

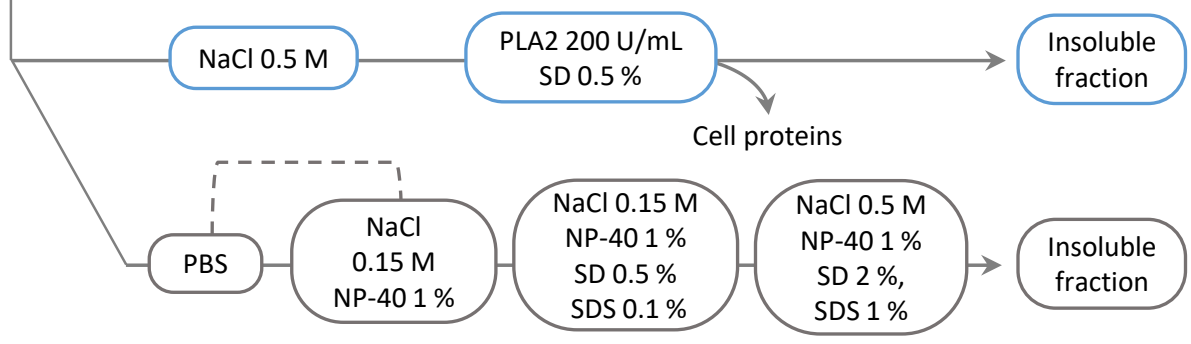

1. Compartmental enrichment

2. Chemical decellularization

3. Enzymatic decellularization

4. QDSP 
Figure 2

A

Chemical decel.

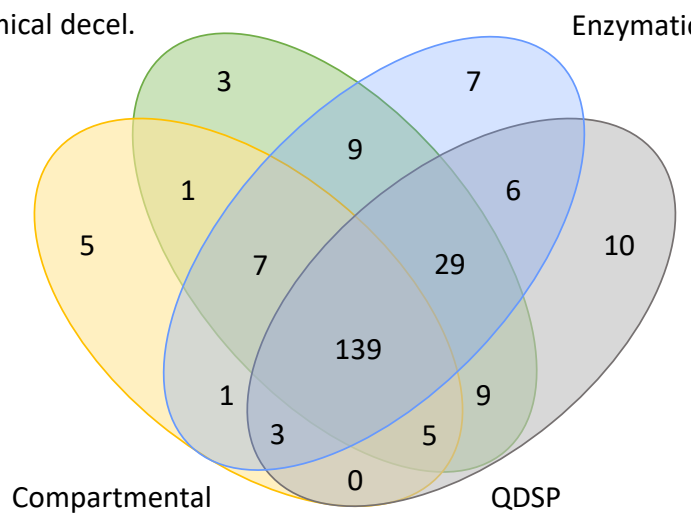

B
Ins.
- GuHCl+Ins.
n Ins.
- SDS/SD
PLA2/SD
- Buffer 3
Buffer C
$\mathrm{NaCl}$
$\mathrm{NaCl}$
- Buffer 2
PBS+Buffer 1

Ins.

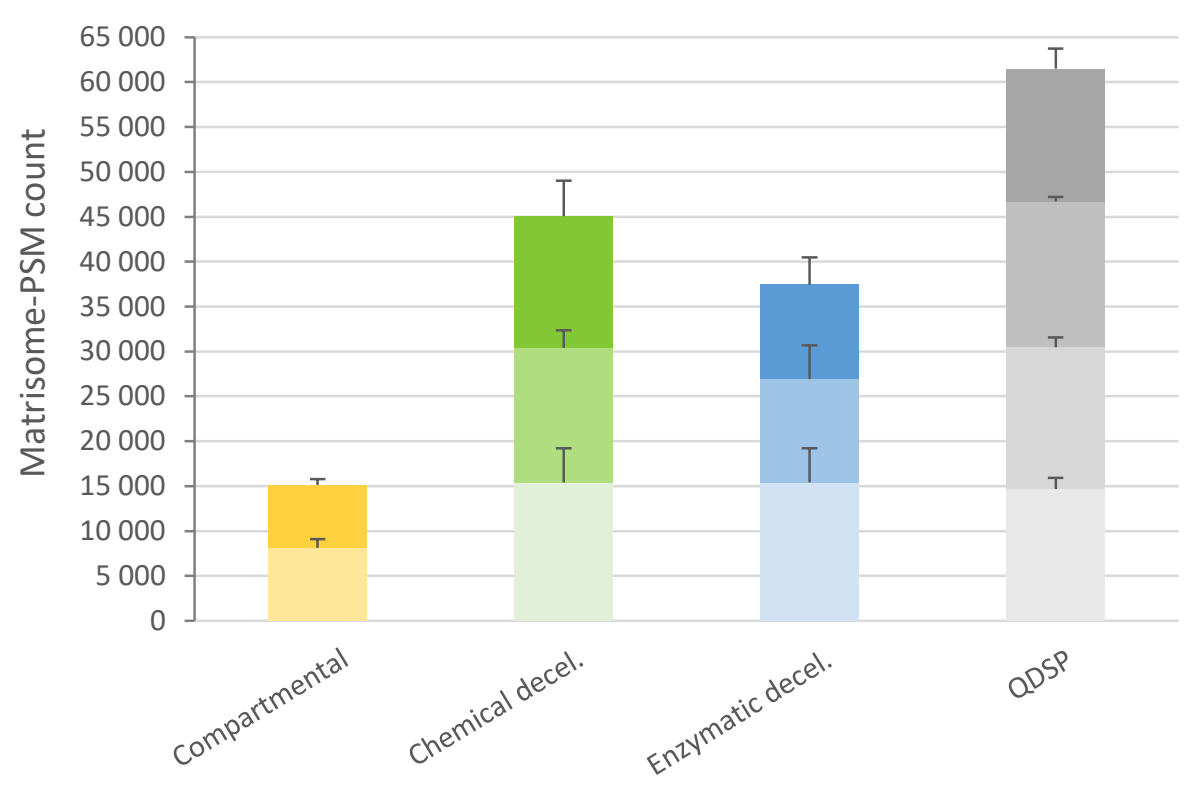

C

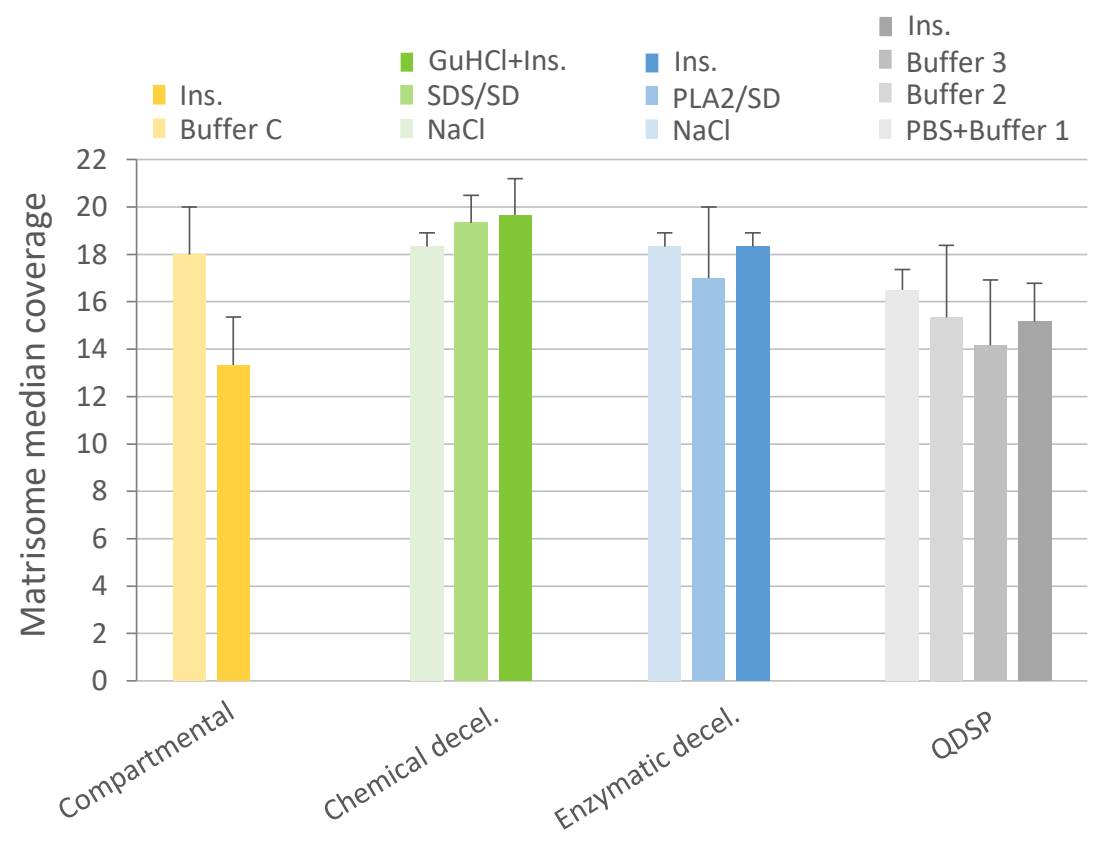


Figure 3

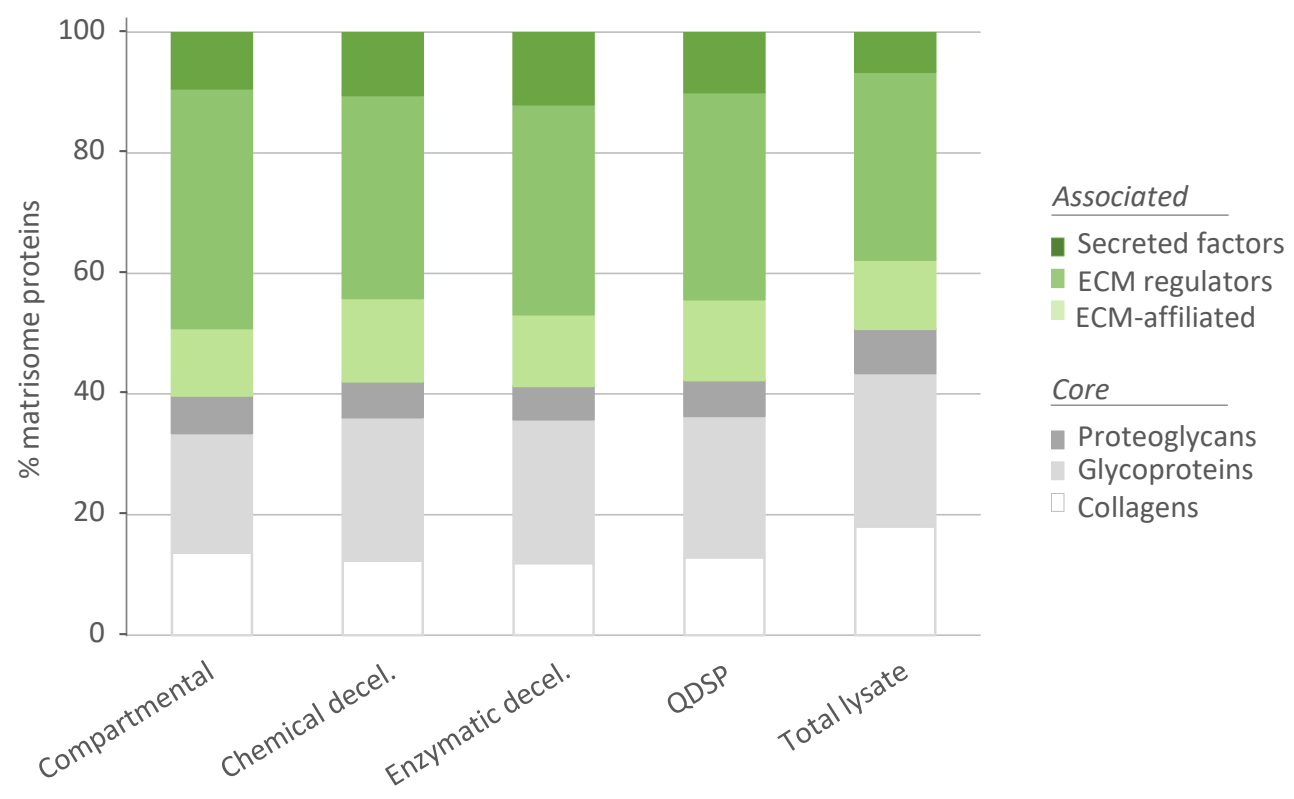



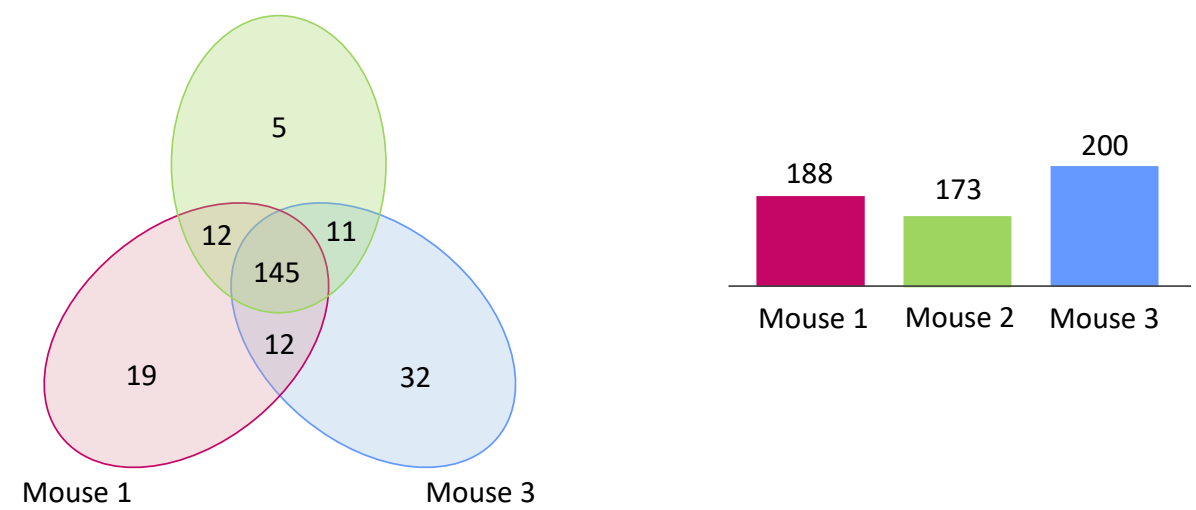

B

Mouse1 Mouse2 Mouse3

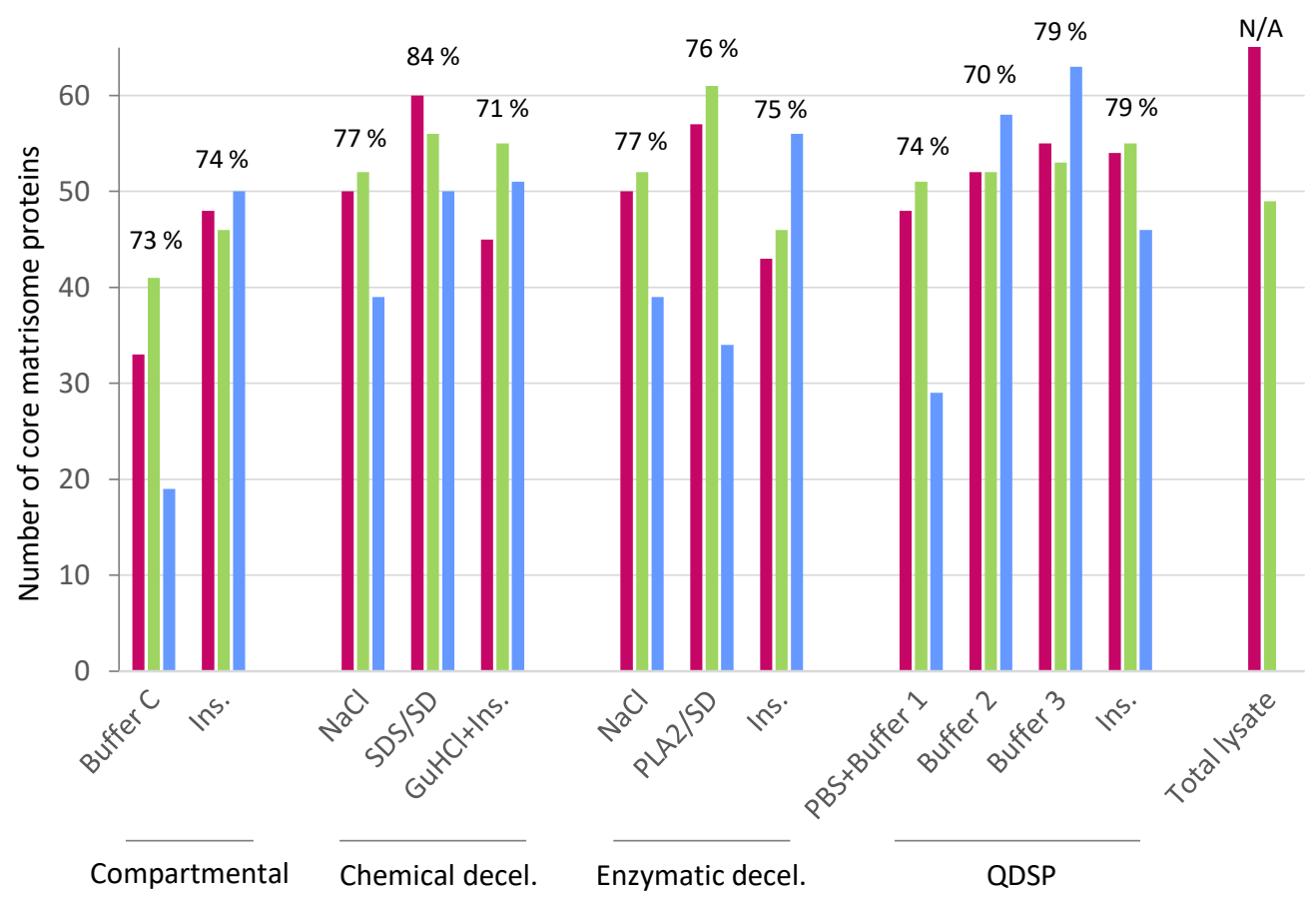

C

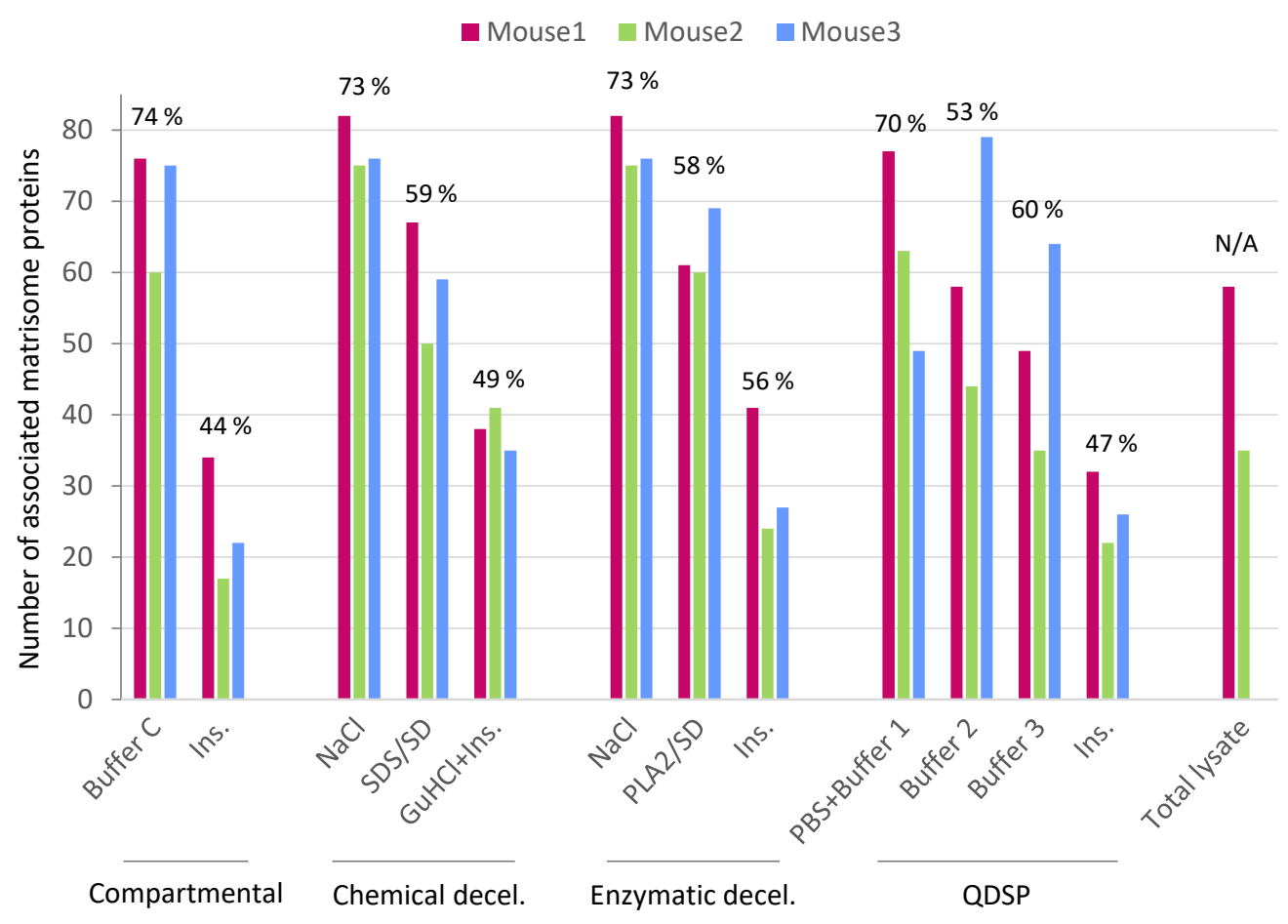


Figure 5

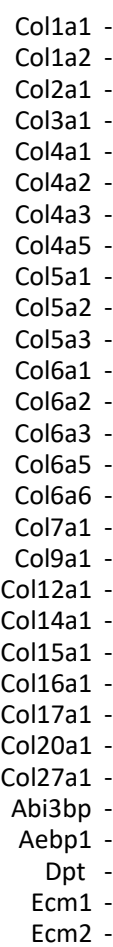

Col1a2 -

Col3a1 -

Col4a1 -

Col4a2 -

Col5a1 -

Col5a2 -

Col6a2 -

Col6a3 -

Col7a1 -

Col9a1 -

Col14a1 -

Col15a1 -

Col16a1 -

Col17a1 -

Col20a1 -

Abi3bp -

Aebp1 -

Ecm1 -

Efemp1 -

Eln -

Emilin1 -

Fbln5 -

Fbn1 -

Fga -

Fgb -

Fgg -

Fn1 -

Lama2 -

Lama3 -

Lama4 -

Lama5 -

Lamb2 -

Lamb3 -

Lamc1 -

Lamc2 -

Mfap2 -

Mfap4 -

Mfap5 -

Nid1 -

Nid2 -

Papln -

Postn -

Sparc -

Srpx -

Tgfbi -

Tnc -

Tnxb -

Vwa5a -

Aspn -

Bgn -

Dcn -

Hspg2 -

Lum -

Ogn -

Podn -

Prelp -

Prg2 -

Vcan -

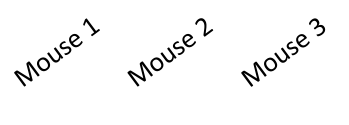

Compartmental

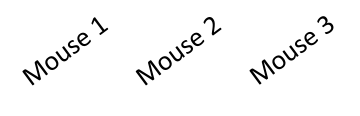

Chemical decel.

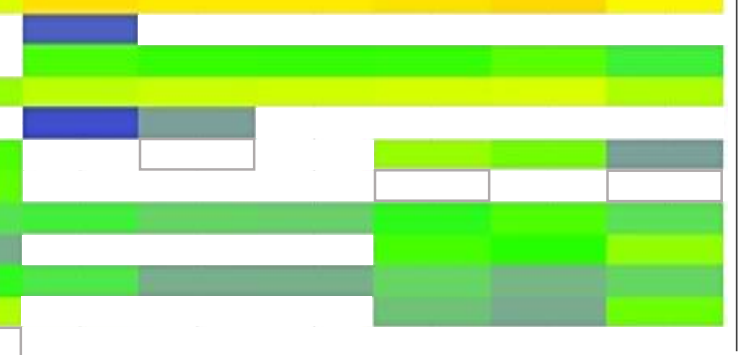

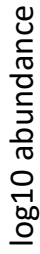

\section{Collagens}

Glycoproteins

Proteoglycans

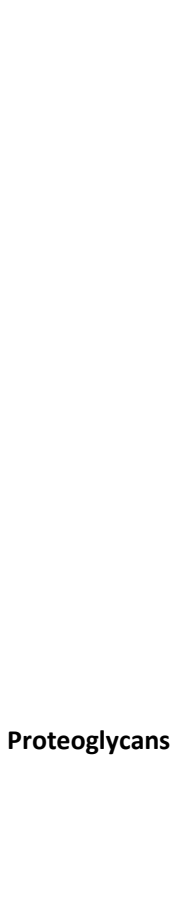

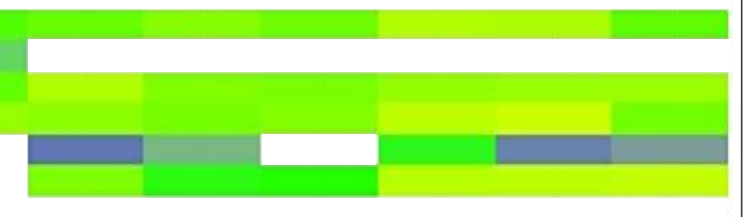
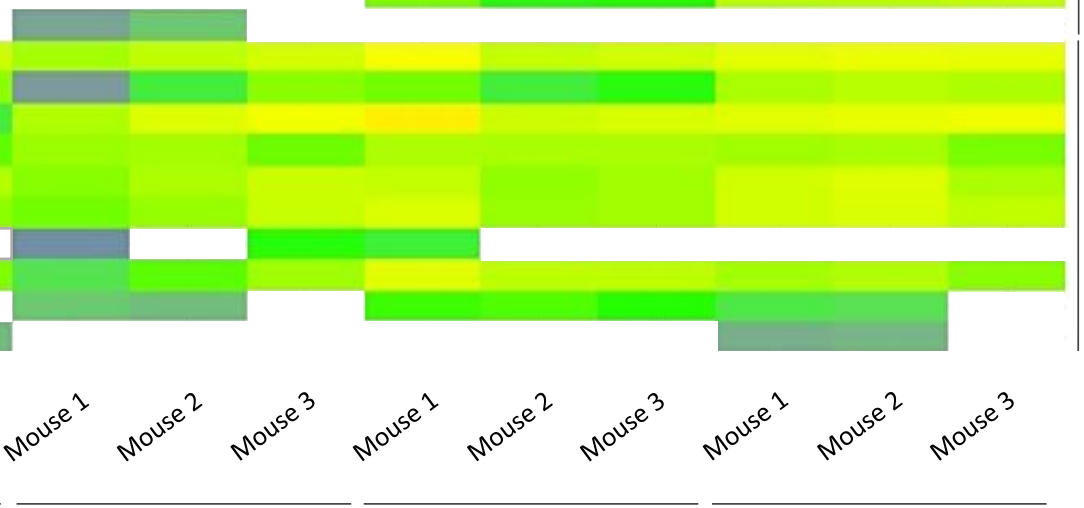

Enzyme decel. 
Matrisome proteins, all protocols

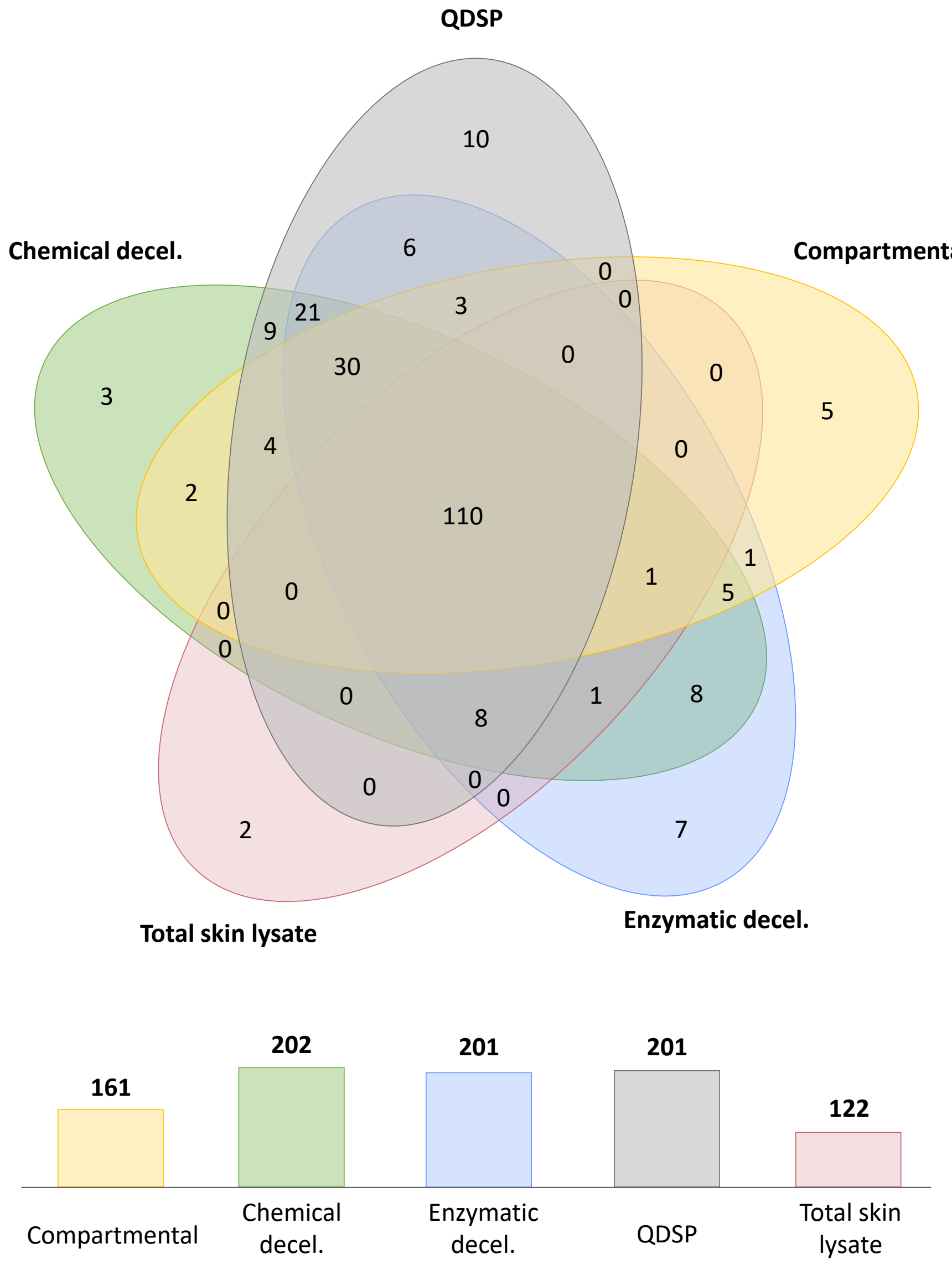


Figure S2

Matrisome proteins, Compartmental enrichment

Buffer C
76

26
Insoluble 
Figure S3

Matrisome proteins, Chemical decellularization enrichment,

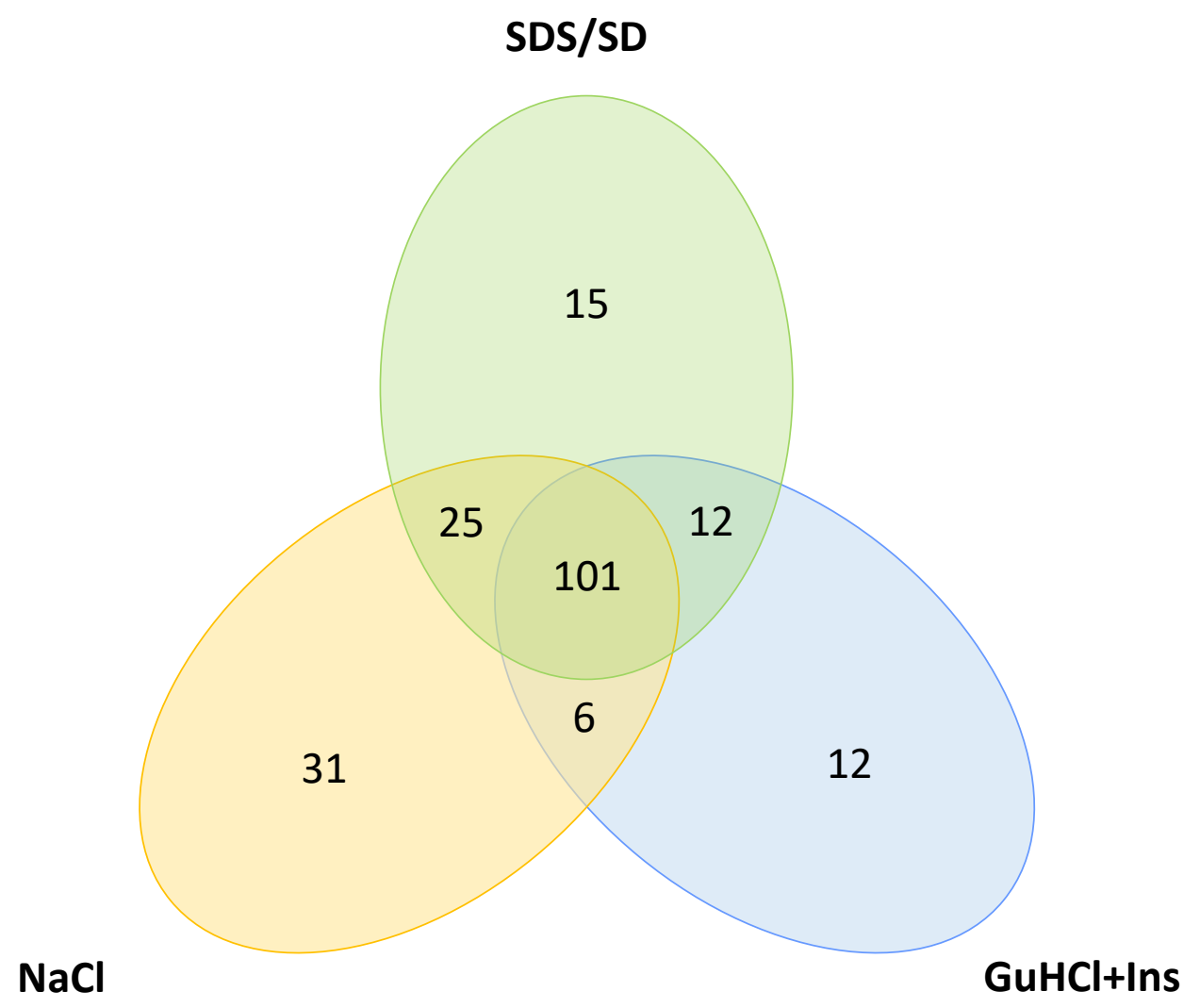


Figure S4

Matrisome proteins, Enzymatic decellularization enrichment

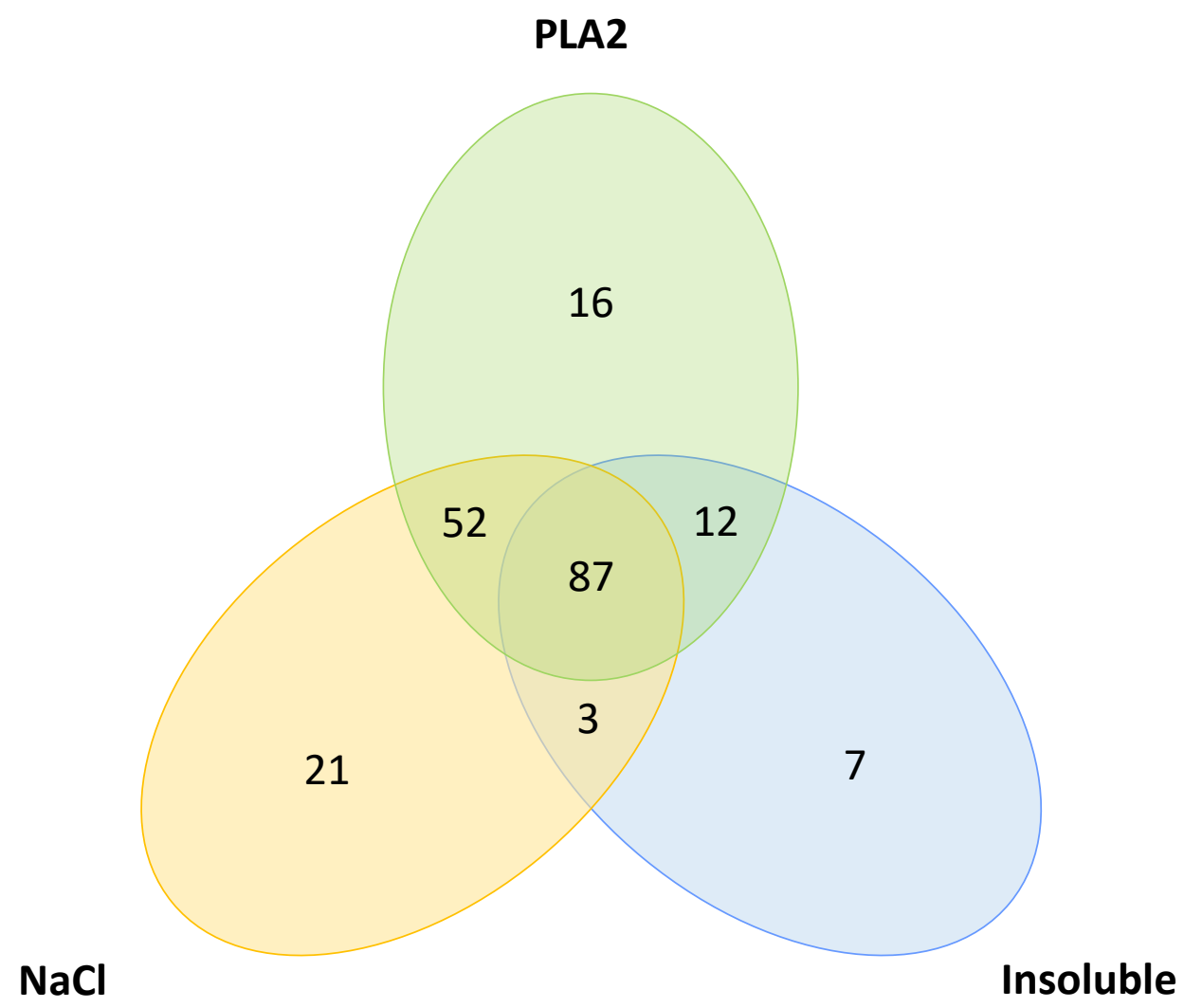


Figure S5

Matrisome proteins, QDSP

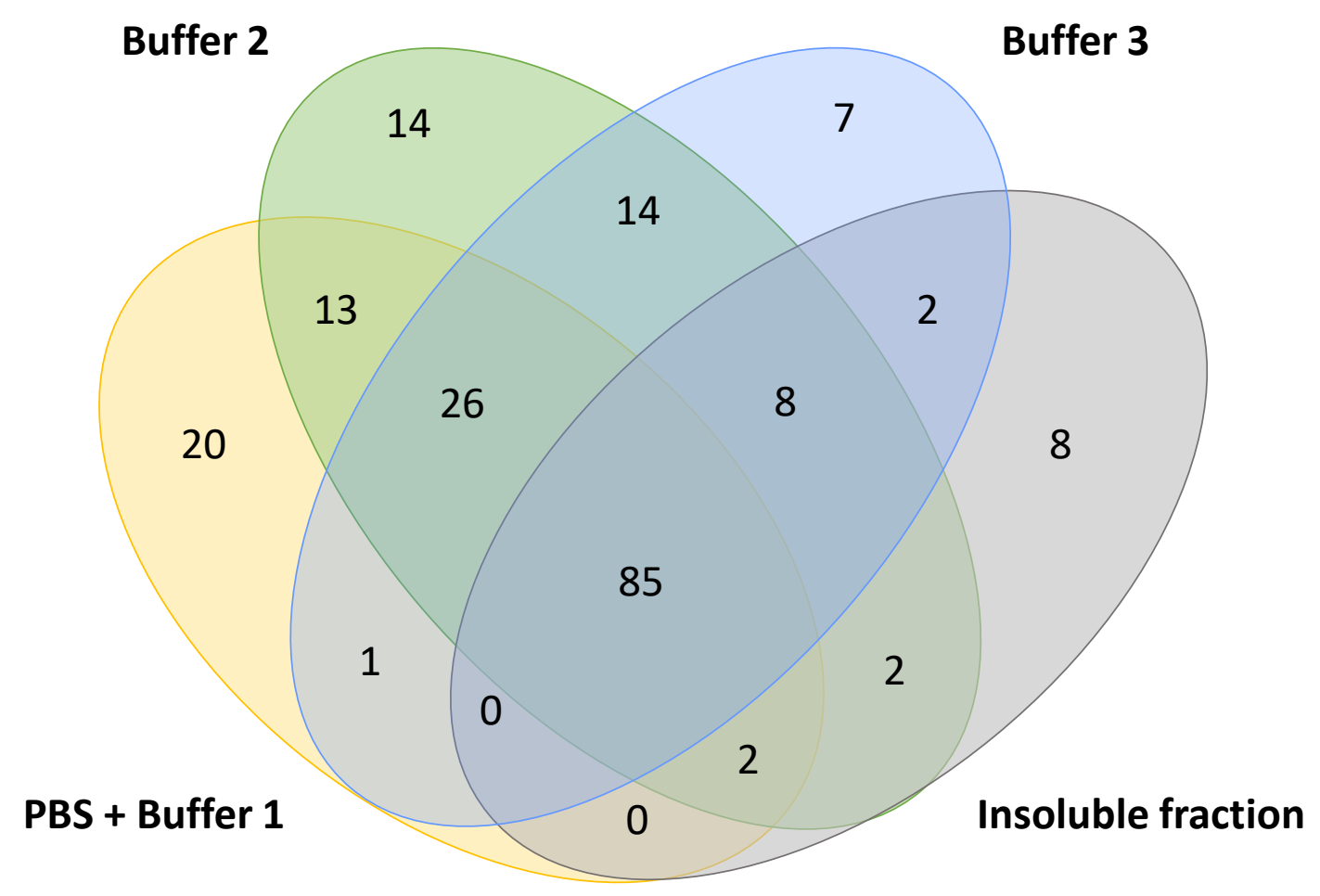


Figure S6

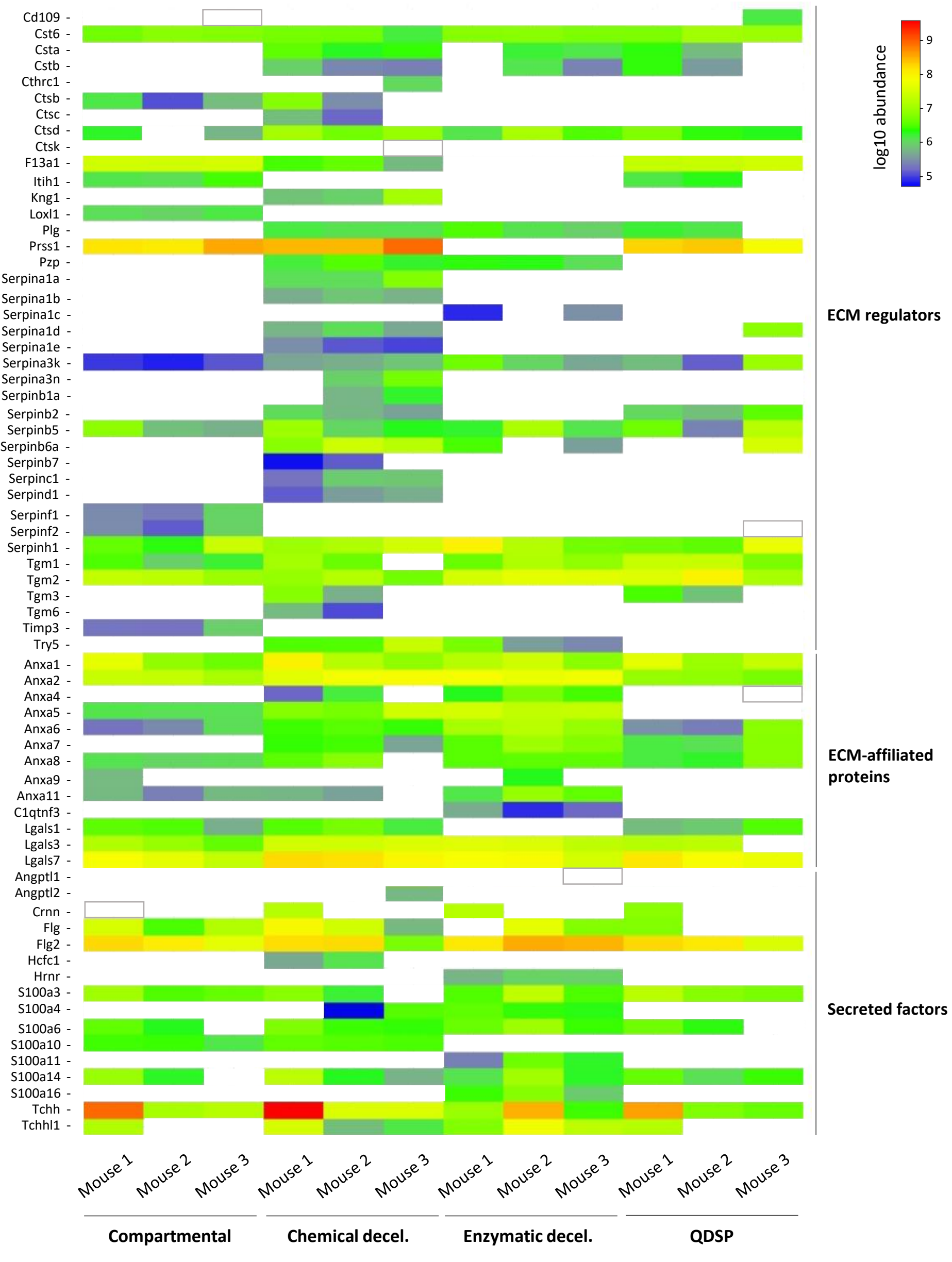

